Article

\title{
A Newfangled Collagenase Inhibitor Topical Formulation Based on Ethosomes with Sambucus nigra L. Extract
}

\author{
Ana Henriques Mota ${ }^{1}$, Inês Prazeres ${ }^{2,3}$, Henrique Mestre ${ }^{1}$, Andreia Bento-Silva ${ }^{1}$, Maria João Rodrigues ${ }^{4}$, \\ Noélia Duarte ${ }^{1} \mathbb{D}$, Ana Teresa Serra 2,3 ${ }^{\mathbb{D}}$, Maria Rosário Bronze 1,2,3 ${ }^{\mathbb{D}}$, Patrícia Rijo 1,5 $\mathbb{D}$, Maria Manuela Gaspar ${ }^{1}$,

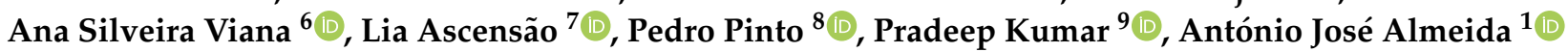 \\ and Catarina Pinto Reis $1,10, * \mathbb{D}$
}

check for

updates

Citation: Mota, A.H.; Prazeres, I.; Mestre, H.; Bento-Silva, A.; Rodrigues, M.J.; Duarte, N.; Serra, A.T.; Bronze, M.R.; Rijo, P.; Gaspar, M.M.; et al. A Newfangled Collagenase Inhibitor Topical Formulation Based on Ethosomes with Sambucus nigra L. Extract. Pharmaceuticals 2021, 14, 467. https://doi.org/10.3390/ph14050467

Academic Editor: Thomas Efferth

Received: 15 April 2021

Accepted: 12 May 2021

Published: 15 May 2021

Publisher's Note: MDPI stays neutral with regard to jurisdictional claims in published maps and institutional affiliations.

Copyright: (c) 2021 by the authors. Licensee MDPI, Basel, Switzerland. This article is an open access article distributed under the terms and conditions of the Creative Commons Attribution (CC BY) license (https:/ / creativecommons.org/licenses/by/ $4.0 /)$.
1 iMED.Ulisboa, Research Institute for Medicines, Faculdade de Farmácia, Universidade de Lisboa, Av. Prof. Gama Pinto, 1649-003 Lisboa, Portugal; ana.luisa.mota@campus.ul.pt (A.H.M.); henriquemestre@campus.ul.pt (H.M.); abentosilva@ff.ulisboa.pt (A.B.-S.); mduarte@ff.ulisboa.pt (N.D.); mrbronze@ff.ulisboa.pt (M.R.B.); patricia.rijo@ulusofona.pt (P.R.); mgaspar@ff.ulisboa.pt (M.M.G.); aalmeida@ff.ulisboa.pt (A.J.A.)

2 IBET, Instituto de Biologia Experimental e Tecnológica, Av. da República, Estação Agronómica, Apartado 12, 2780-901 Oeiras, Portugal; ines.prazeres@ibet.pt (I.P.); tserra@ibet.pt (A.T.S.)

3 Instituto de Tecnologia Química e Biológica António Xavier, Universidade Nova de Lisboa (ITQB NOVA), Av. da República, 2780-157 Oeiras, Portugal

4 Centre of Marine Sciences, Faculty of Sciences and Technology, University of Algarve, Ed. 7, Campus of Gambelas, 8005-139 Faro, Portugal; mary_p@sapo.pt

5 CBiOS - Research Center for Biosciences \& Health Technologies, Universidade Lusófona de Humanidades e Tecnologias, Campo Grande 376, 1749-024 Lisboa, Portugal

6 Centro de Química Estrutural, Faculdade de Ciências, Universidade de Lisboa,

Campo Grande, 1749-016 Lisboa, Portugal; apsemedo@fc.ul.pt

7 Centro de Estudos do Ambiente e do Mar (CESAM), Faculdade de Ciências, Universidade de Lisboa, Campo Grande, 1749-016 Lisboa, Portugal; lmpsousa@fc.ul.pt

8 PhDTrials-International Contract Research Organization, Av. Maria Helena Vieira da Silva nº 24 A, 1750-182 Lisboa, Portugal; pcontreiras@sapo.pt

9 Wits Advanced Drug Delivery Platform Research Unit, Department of Pharmacy and Pharmacology, School of Therapeutic Sciences, Faculty of Health Sciences, University of the Witwatersrand, Johannesburg 2193, South Africa; pradeep.kumar@wits.ac.za

10 IBEB, Biophysics and Biomedical Engineering, Faculdade de Ciências, Universidade de Lisboa, 1749-016 Lisboa, Portugal

* Correspondence: catarinareis@ff.ulisboa.pt; Tel.: +351-21-794-6400

Abstract: Sambucus nigra L. (S. nigra) is a shrub widespread in Europe and western Asia, traditionally used in medicine, that has become popular in recent years as a potential source of a wide range of interesting bioactive compounds. The aim of the present work was to develop a topical S. nigra extract formulation based on ethosomes and thus to support its health claims with scientific evidence. S. nigra extract was prepared by an ultrasound-assisted method and then included in ethosomes. The ethosomes were analyzed in terms of their size, stability over time, morphology, entrapment capacity (EC), extract release profile, stability over time and several biological activities. The prepared ethosomes were indicated to be well defined, presenting sizes around $600 \mathrm{~nm}$. The extract entrapment capacity in ethosomes was $73.9 \pm 24.8 \%$, with an interesting slow extract release profile over $24 \mathrm{~h}$. The extract-loaded ethosomes presented collagenase inhibition activity and a very good skin compatibility after human application. This study demonstrates the potential use of S. nigra extract incorporated in ethosomes as a potential cosmeceutical ingredient and on further studies should be performed to better understand the impact of $S$. nigra compounds on skin care over the time.

Keywords: Sambucus nigra L.; ethosomes; collagenase inhibition; skin compatibility 


\section{Introduction}

The skin constitutes the interface between the organism and the external environment, acting as an epidermal barrier, protecting and supporting the life that it encloses. It presents three different layers (epidermis, dermis and hypodermis). The epidermis in turn can be divided in distinct layers: stratum corneum, lucidum, granulosum, spinosum and basale [1-3].

Over the years, skin disorders have been emerging, affecting millions of people particularly in developing countries. Several factors can disturb this barrier function by damaging the stratum corneum (SC). These factors are associated with ultrastructural anomalies in the upper granular layer [1], related to a change of integrity of the skin layers and respective structures. These disorders can appear due to many factors, underlying medical conditions and other pathologies, such as inflamed skin, infections, chronic inflammatory skin disorders (e.g., psoriasis), sensitive skin (e.g., allergic contact dermatitis, atopic dermatitis, seborrhea dermatitis or rosacea), among others [1]. Inflamed skin is generally characterized by redness, swelling, itching, heat and pain [2]. The cause or trigger for skin inflammation may be acute or chronic. Most cases are curable, and the treatment depends on what is causing the inflammation. On the other hand, skin infections occur when bacteria, virus, fungus or other foreign substances enter the skin through a wound or cut. These can lead to several diseases like cellulitis, impetigo, staphylococcal infections, shingles, warts, yeast infections, among others. Symptoms include swelling, redness, pain, irritation, itching and burning sensation. Finally, sensitive skin is described as a discomfort situation with stinging, burning or tingling sensations and sometimes it can be very painful and itch [2]. Thus, finding new protective bioactive ingredients that can help in skin care is crucial.

S. nigra has been used in traditional medicine for several purposes $[4,5]$. One of them is related to its microbiological properties. Recent studies reported that a flower extract of $S$. nigra has several important biological activities, such as anti-inflammatory properties and collagenase (Coll)-inhibitory activity [4,5]. Coll is a matrix metalloprotease (MMP) enzyme responsible for the degradation of collagen $[5,6]$. In general, this enzyme is produced by fibroblasts like synoviocytes [6], and the degradation of the extracellular matrix by Coll has an important part in the invasion of tumor cells [7]. Collagen can be classified in different types, being collagen type I, the most abundant protein of the skin [8] and collagen I and III fibrils, responsible for the strength and resiliency of the skin. The skin aging is associated with an overexpression of Coll activity [9], as well as a reduced production of type I and III collagen as well as an abundance of degraded and disorganized collagen fibrils $[8,10]$. Furthermore, tumor cells may induce host cells to produce Coll [7]. In this sense, like many other species, elderflower extracts might have some potential and interesting properties against skin aging, although, its direct skin application can be compromised by thermal degradation [11], or by photodegradation which might affect its phenolic content [12] Thus, the encapsulation or entrapment of extracts using protective carriers may present several advantages $[4,13]$. The characterization of the extract was already performed by our research group $[4,5]$. It was possible to identify malic acid, rutin, isoquercetin, isorhamnetin3-O-glucoside, naringenin, quercetin-4-O-glucoside, isorhamnetin-3-rutinoside and luteolin7-O-glucoside (see Supplementary Material Figure S1).

Nanotechnology has been used in the delivery of therapeutic agents or active ingredients through the skin. Among nanocarriers, vesicular systems are frequently used, since they present many advantages as enhancer agents of the stability of loaded agents, preventing its degradation and improving its penetration across the skin. These advantages are a consequence of their size, elasticity and lipid content, which allows to interact with the SC [2]. Among vesicles, ethosomes represent the third generation of elastic lipid carriers. They are phospholipid nanovesicles with ability to overcome the natural dermal barrier and capacity to delivery drugs through the skin layers. Ethosomes are constituted by phospholipids (20-45\%), water and high concentrations of short chain alcohols (in general between $20-45 \%$ ethanol) and isopropyl alcohol or propylene glycol (up to $15 \%$ ). A contributing factor that could explain the enhanced delivery when compared with other vesicles, such 
as liposomes, is the presence of ethanol, a known permeation enhancer, which provides ultradeformability. Ethanol is interspersed in the intercellular lipids, enhancing the lipid fluidity and decreasing the density of the lipid multilayer, event that is known as "ethanol effect". Afterwards, the "ethosomes effect" occurs, consisting of the interlipid penetration and permeation by the opening of new pathways due to the malleability and fusion of these nanovesicles with skin lipids. Thus resulting in the release of bioactive compounds into the deep layers of the skin [14].

This study aimed to develop a possible ultradeformable skin carrier for Sambucus extract, to protect the bioactive compounds from degradation and to obtain a slow bioactive compound release $[1-3,15,16]$.

\section{Results and Discussion}

\subsection{Physical Characterization of Ethosomes}

Empty and extract-loaded ethosomes were successfully produced and then characterized in terms of size, polidispersity index (PdI) and $\mathrm{pH}$. This characterization was also performed for stored particles at three different temperatures: refrigerated conditions (RC), room temperature (RT) and accelerated conditions (AC) for 12 months as depicted in Figure 1.

It is noteworthy that an increase of the size was observed after the extract encapsulation. The temperature of storage had influence on particle size. After loading the particle size of extract-loaded ethosomes was $630.1 \pm 113.8 \mathrm{~nm}$ at RC (0 months) and $573.3 \pm 192.3 \mathrm{~nm}$ (0 months) at AC, but a slight decrease was observed after 12 months in storage. The final particle size was $580.7 \pm 57.1 \mathrm{~nm}$ and $549.8 \pm 147.4 \mathrm{~nm}$ for RC and AC, respectively. However, at RT, the extract-loaded ethosomes presented an increase of the particle size from $601.6 \pm 103.6 \mathrm{~nm}$ to $726.4 \pm 133.6 \mathrm{~nm}$ (12 months). But, in all cases, those changes were very small in particular at AC. The particle size has influence in many properties of particulate materials, being a crucial key factor for quality and performance of the formulation $[4,17]$. It is very important to maintain this parameter over the time and to control the tendency of creating agglomerates.

In terms of the PdI, at RC, the extract-loaded ethosomes presented a slight increase of PdI from $0.725 \pm 0.086$ ( 0 months) to $0.784 \pm 0.111$ (12 months). While, at RT and AC there was a reduction of the PdI, from $0.731 \pm 0.116$ ( 0 months) to $0.707 \pm 0.194$ (12 months) and $0.755 \pm 0.111$ ( 0 months) to $0.569 \pm 0.210$ (12 months), respectively.

In terms of $\mathrm{pH}$, after the extract encapsulation, a decrease of the $\mathrm{pH}$ was verified. Concerning the $\mathrm{pH}$ values, the extract-loaded ethosomes suspension revealed differences $(p<0.001)$ over time at RC and at AC. Less evident differences were observed at RT with a $p<0.01$ ( $0-12$ months). This data is in accordance with previous studies where the $\mathrm{pH}$ values were $4.11 \pm 0.04$ and $3.90 \pm 0.03$, for empty and rutin-loaded ethosomes, respectively [18].

Finally, the zeta potential analysis showed that the empty and extract-loaded ethosomes presented negative charge. When comparing both, i.e., empty and loaded ethosomes, the results suggest that the extract encapsulation led to an increase of the negative charge of the ethosomes.

As section summary, the extract-loaded ethosomes were stable over time in terms of size and $\mathrm{pH}$. The temperature of storage had influence on the tested parameters especially on PdI. The extract-loaded ethosomes showed a better stability at RT in terms of size, PdI, $\mathrm{pH}$ and zeta potential when compared with other temperatures.

\subsection{Lipid Quantification of Ethosomes}

Considering the nature of these carriers, lipid composition was determined to correctly assess the amount of ethosomes for the next studies. The calibration curve was established between 10 and $80 \mathrm{nmol} /$ tube ( $y=0.013 x+0.0033$ with a $R^{2}$ of 0.9996$)$. The theoretical concentration for this formulation was of $25.95 \mu \mathrm{mol} / \mathrm{mL}$. However, the obtained result suggested a concentration of $28.33 \mu \mathrm{mol} / \mathrm{mL}$. Thus, the result was near the empiric concentration. 


\subsection{Histochemical Characterization of Ethosomes Lipidic Constitution and of Their Morphology}

In light microscopy, the empty ethosomes in suspension state had the appearance of small spherical granules (Figure 2a). After staining with Nile blue A (a stain for in situ detection of all the major classes of cellular lipids), they stained blue, indicating the presence of acidic lipids (Figure 2b). Neutral lipids generally stain red with this histochemical test. When Nile Blue A was used as a fluorochrome, an intense bright red fluorescence was observed under green light (Figure 2c) which confirms the lipidic constitution of ethosomes.

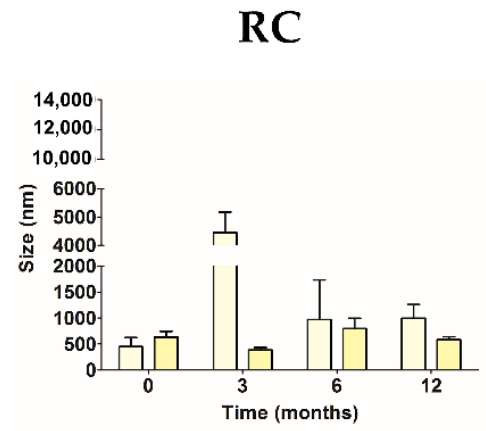

(a)

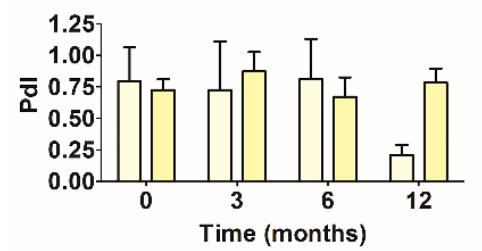

(d)

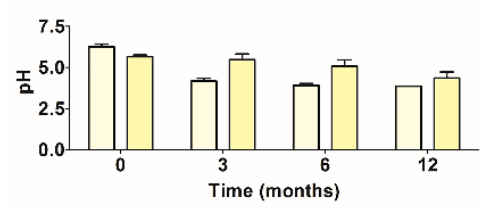

(g)

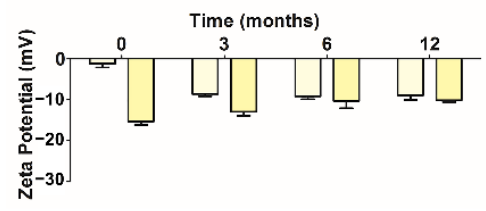

(j)

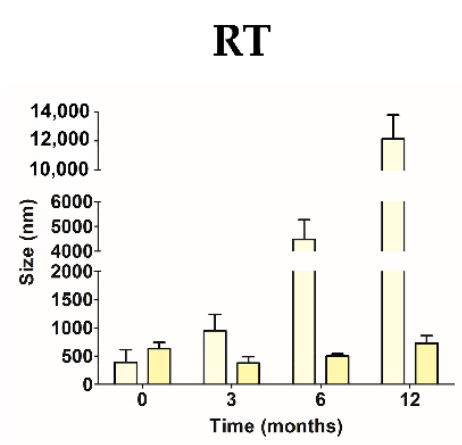

(b)

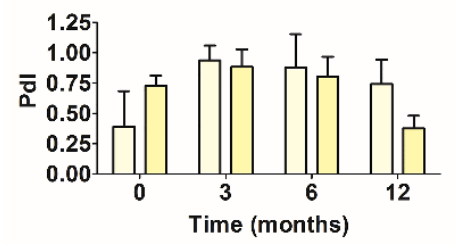

(e)

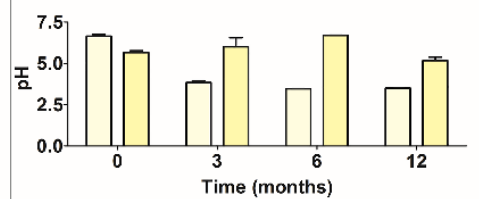

(h)

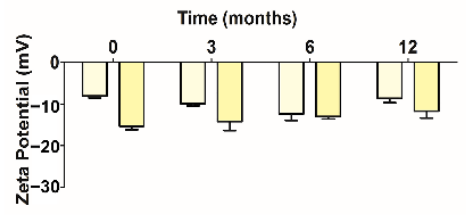

(k)
AC

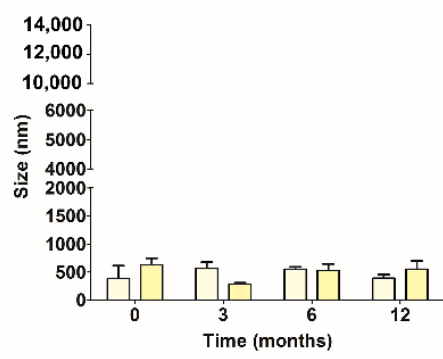

(c)

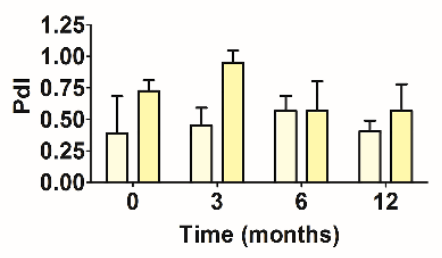

(f)

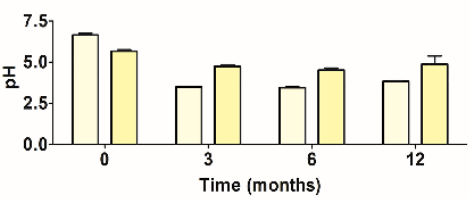

(i)

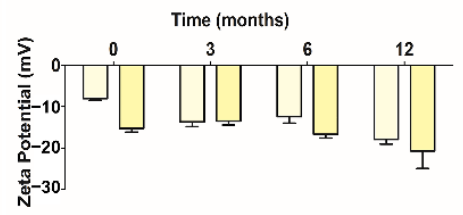

(l)

Figure 1. (a-1) Variation of mean size, PdI, $\mathrm{pH}$ and zeta potential over the time (0,3, 6 and 12 months) of empty ethosomes (light yellow columns) and extract-loaded ethosomes (dark yellow columns) using different temperature of storage, namely, RC, RT and AC (mean \pm S.D., $n=9)$.

The micrographs obtained with Nile blue support the quantification of lipids determined previously, where the same tendency was observed. In Figure 2c, the amount of red points was significant, revealing an important amount of lipids into the formulation, which corresponds to the phosphatidylcholine (SPC) used.

Furthermore, empty and extract-loaded ethosomes were observed by scanning and transmission electron microscopy (SEM and TEM), as well as by atomic force microscopy (AFM). By SEM, all ethosomes presented a spherical or a very near-spherical-shape and a smooth surface (Figure 3a,b). The morphology of ethosomes does not seem to change after entrapment of the extract. TEM observations also showed spherical shaped unilamellar vesicles (Figure 3c,d), confirming the results obtained by Dynamic Light Scattering (DLS). 
By AFM (Figure 4), another technique and sample treatment, sizes between ca 140 and $350 \mathrm{~nm}$ were observed for empty ethosomes, whereas extract-loaded ones exhibited approximately $300 \mathrm{~nm}$, as represented in the cross-section profiles of Figure 4b,d. Overall, the sizes observed by AFM were lower than the ones determined by DLS. AFM generally delivers a high contrast images and signal to noise ratio. However, it can be very sensitive to cleanliness of the samples [19]. In case of DLS, this technique measures Brownian motion and relates to the hydrodynamic diameter. This value refers to how a particle diffused within a fluid and it strongly depends on the particle "core", particle surface as well the concentration and type of the ions in that medium that forms a double layer. These ions can influence the thickness of the electric double layer. All techniques showed that empty and extract-loaded ethosomes exhibited a spherical or near-spherical-shape, which is a good indicator for the potential topical use, since the surface area versus volume should be high in principle [20].
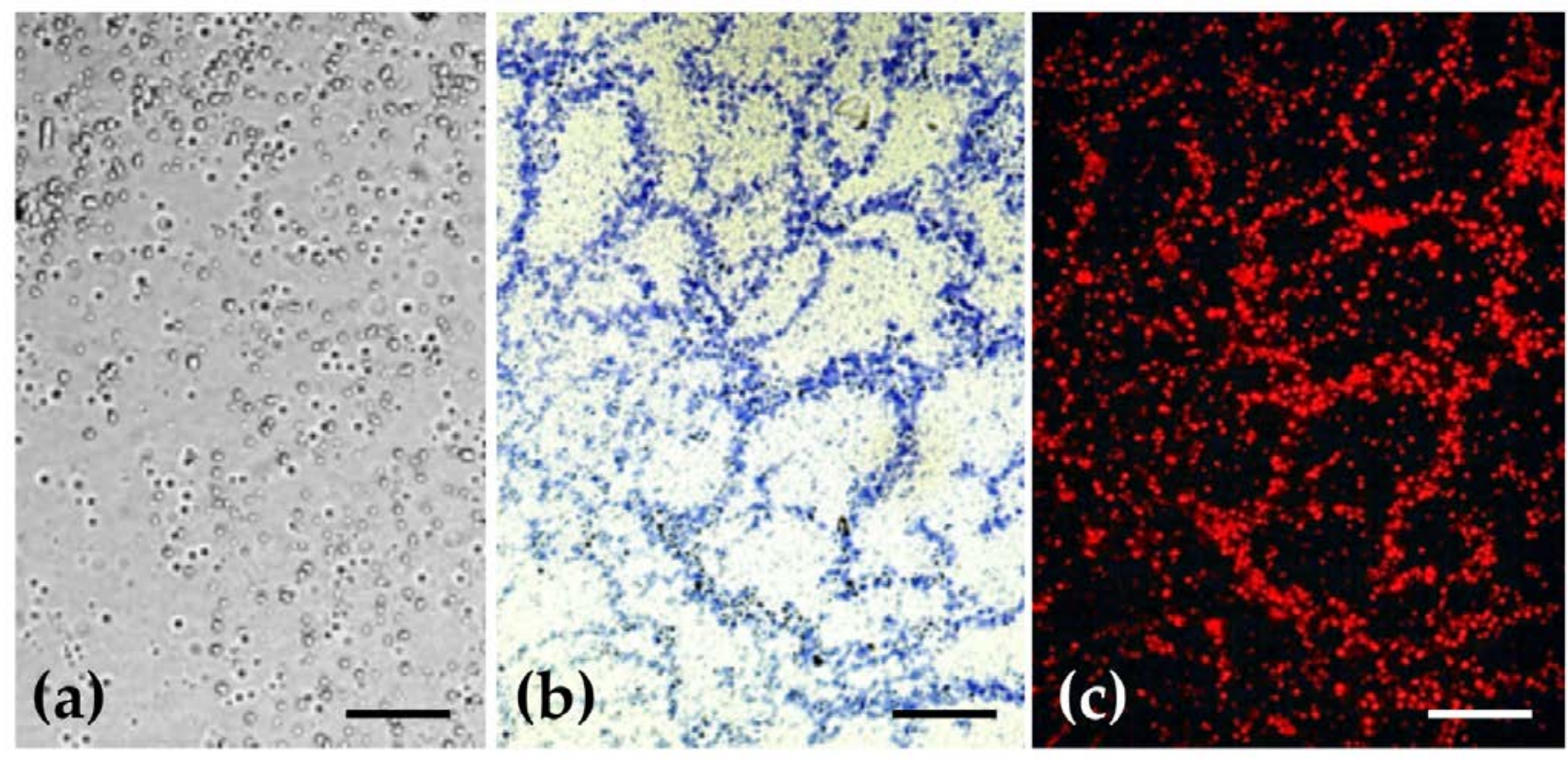

Figure 2. Light micrographs of empty ethosomes. (a) Unstained and observed with Nomarsky optics; (b) Stained with Nile blue A and observed under bright field illumination; (c) Stained with Nile blue A and observed under green light. Note the bright red secondary fluorescence of lipids. Scale bars $=5 \mu \mathrm{m}$.

\subsection{Entrapment Capacity of Extract in Ethosomes}

The entrapment capacity (EC) was determined for extract-loaded ethosomes using rutin as reference (Figure 5). Rutin is the major phenolic compound of this extract $(74.93 \pm 17.00 \mathrm{mg} / \mathrm{g}$ of extract). This observed value is in accordance with the values found in literature [21-23]. In the current study, the ethosomes presented an EC of $73.91 \pm 24.80 \%$ $(n=20)$ which might be a good indicator of the presence of stable interactions between extract and SPC. Besides other factors, the EC is generally dependent on the composition of ethosomes [24-26]. In previous works with similar composition of ethosomes, the value ranged between $65 \%$ and $71 \%$ of rutin [26-28], similar to our value.

\subsection{Characterization of Rutin and Ethosomes Complexes}

Table 1 displays the inherent molecular energy attributes for various biomolecular complexes (SPC-rutin), while Figure 6 presents the corresponding geometrical positions. Here, the target was the major compound of the extract, rutin. In terms of the overall energy, the SPC-rutin complex was stabilized by the Van der Waals energy and it was accompanied by dihedral and electrostatic destabilizations. Interestingly, this comparatively destabilization of SPC-rutin molecular complex $(\Delta \mathrm{E} \approx-6 \mathrm{kcal} / \mathrm{mol})$ may provide 
enhanced diffusivity of rutin across the lipidic matrix, in comparison to the polymer-rutin complexes in a previous study performed by our group, where poly-glycolic-lactic acidrutin and poly-caprolactone-rutin revealed higher molecular complex $(\Delta \mathrm{E} \approx-20 \mathrm{kcal} / \mathrm{mol}$ and $-18 \mathrm{kcal} / \mathrm{mol}$, respectively) [4]. These chemical interactions might somehow justify the extract entrapment of around $70 \%$, i.e., the interactions are not too strong in terms of energy.
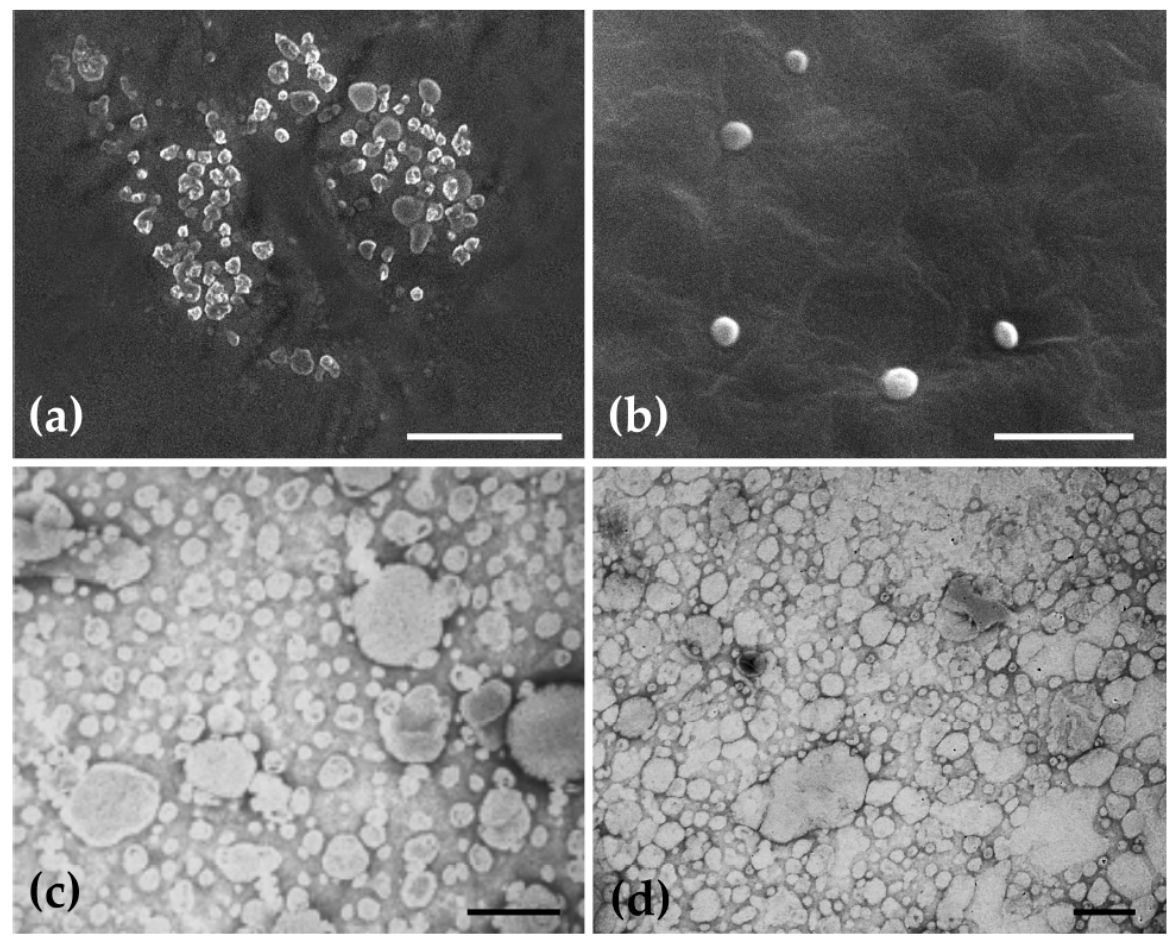

Figure 3. Representative SEM and TEM micrographs showing the morphology of ethosomes. $(\mathbf{a}, \mathbf{b})$ SEM images of empty and extract-loaded ethosomes, respectively. (c,d), TEM images of empty and extract-loaded ethosomes, respectively. Scale bars $=5 \mu \mathrm{m}(\mathbf{a}) ; 3 \mu \mathrm{m}(\mathbf{b}) ; 2 \mu \mathrm{m}(\mathbf{c}, \mathbf{d})$.

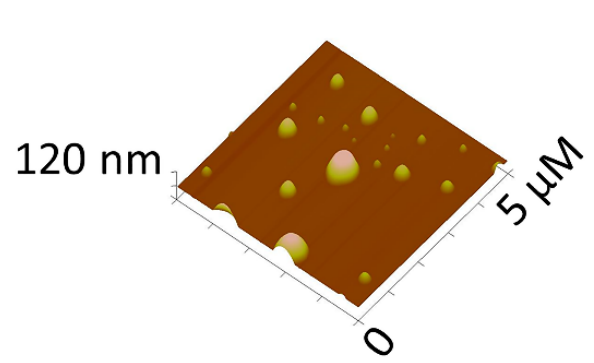

(a)

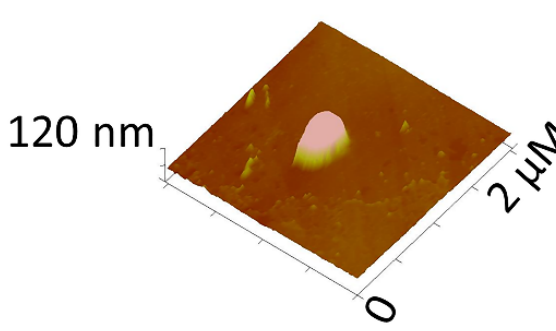

(c)
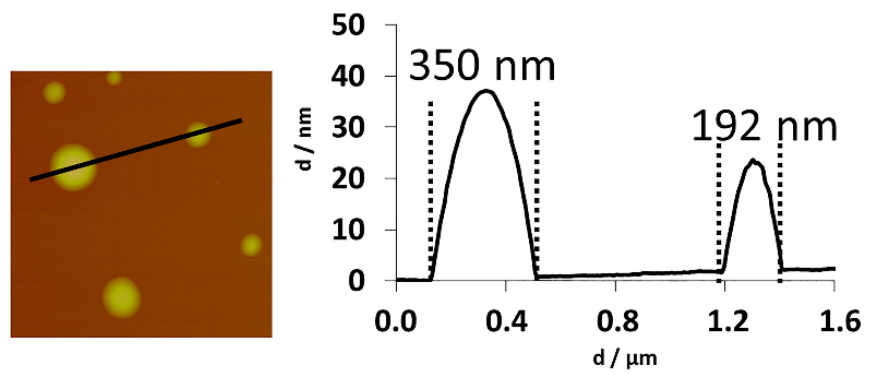

(b)

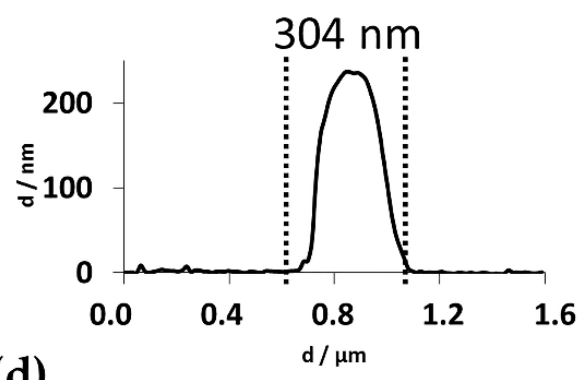

Figure 4. AFM topographic images of ethosomes. $(\mathbf{a}, \mathbf{b})$ empty and $(\mathbf{c}, \mathbf{d})$ extract-loaded. 3D images $(\mathbf{a}, \mathbf{c})$ and cross section analysis $(\mathbf{b}, \mathbf{d})$. 


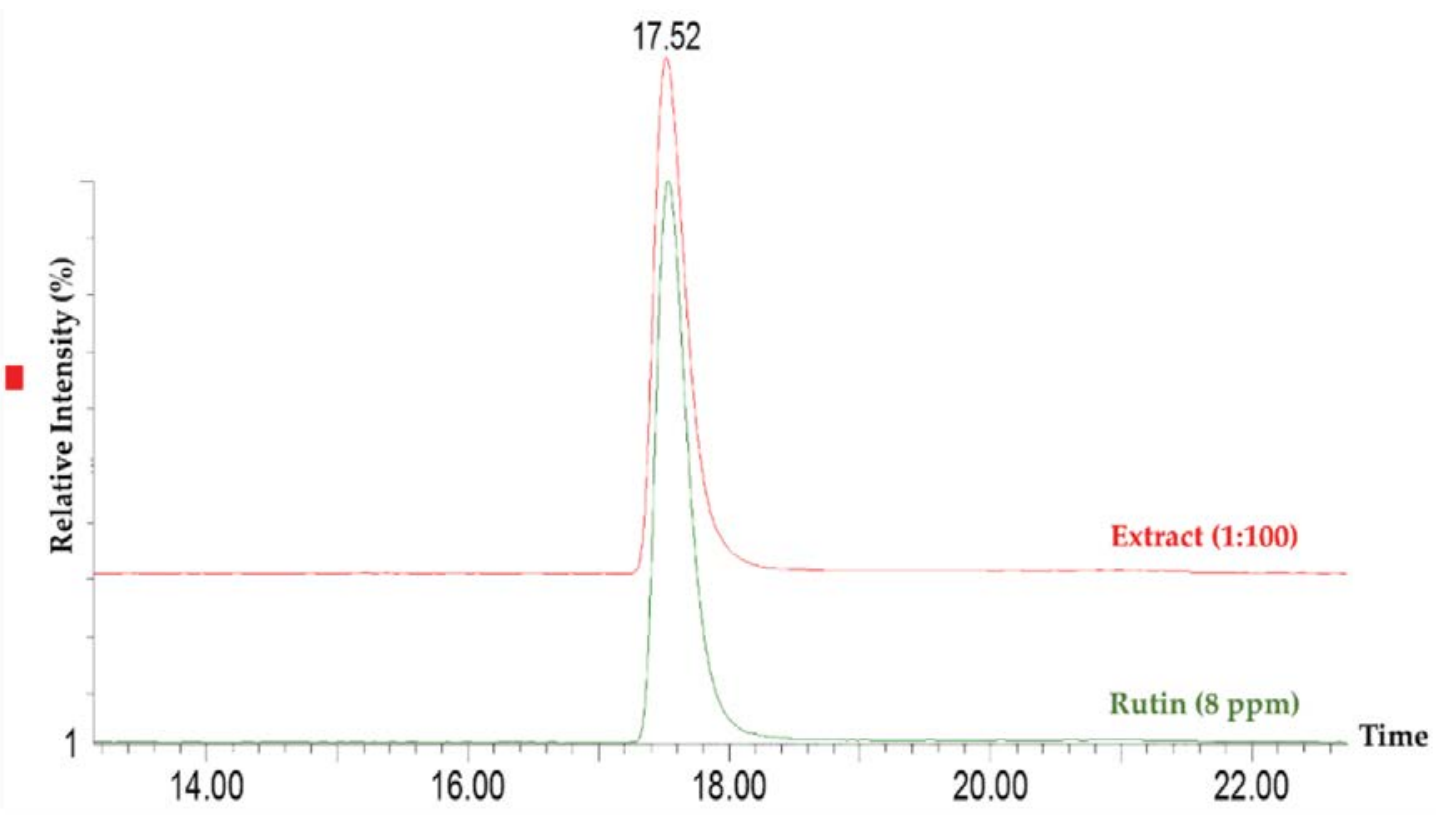

Figure 5. MRM overlay chromatograms of rutin in the extract with a standard solution.

Table 1. Inherent energy attributes of SPC-rutin complexes calculated using static-lattice atomistic simulations (SLAS) in vacuum.

\begin{tabular}{ccccc}
\hline Energy & Rutin & SPC & SPC-Rutin & $\Delta \mathbf{E}^{\mathbf{1}}$ \\
\hline Total $^{2}$ & 23.09 & 1.10 & 18.61 & $-5.58^{8}$ \\
Bond $^{3}$ & 1.16 & 1.39 & 2.49 & $-0.05^{8}$ \\
Angle $^{4}$ & 7.57 & 35.69 & 42.85 & $-0.41^{8}$ \\
Dihed $^{5}$ & 14.32 & 10.28 & 27.60 & $3.00^{9}$ \\
vdW $^{6}$ & 0.04 & -4.25 & -14.35 & $-10.15^{8}$ \\
Elec $^{7}$ & 0.00 & -42.01 & -39.97 & $2.04^{9}$ \\
\hline
\end{tabular}

${ }^{1} \Delta \mathrm{E}(\mathrm{A} / \mathrm{B})=\mathrm{E}(\mathrm{A} / \mathrm{B})-[\mathrm{E}(\mathrm{A})+\mathrm{E}(\mathrm{B})]{ }^{2}{ }^{2}$ total steric energy for an optimized structure; ${ }^{3}$ bond stretching contributions; ${ }^{4}$ bond angle contributions; ${ }^{5}$ torsional contribution arising from deviations from optimum dihedral angles; ${ }^{6}$ Van der Waals interactions; ${ }^{7}$ electrostatic interactions; ${ }^{8}$ values represent the structure stabilizing contribution; and ${ }^{9}$ values represent the structure destabilizing contribution.

\subsection{In Vitro Release Studies of Extract from Ethosomes}

The release profile of extract from ethosomes was performed using PBS at two different $\mathrm{pHs}$, at $\mathrm{pH} 5.5$ which is similar to the $\mathrm{pH}$ of the skin [2], and at $\mathrm{pH} 7.4$ which corresponds to the biological $\mathrm{pH}$ of blood [29]. The assays were performed at controlled room temperature $\left(\mathrm{RT} \approx 25^{\circ} \mathrm{C}\right)$. The obtained results are displayed in Figure 7 . The release studies showed that the extract-loaded ethosomes presented the same release profiles, independently of $\mathrm{pH}$, achieving $83.8 \pm 8.3 \%$ and $82.8 \pm 6.4 \%$, for PBS pH 5.5 and $\mathrm{pH} 7.4$, respectively. This behavior was quite different from the free extract where its complete solubilization instantaneously occurred after $5 \mathrm{~min}$. Here, the extract encapsulation into ethosomes led to a slight delay, which can favor the extract release in the target area. This retention time can be additionally modulated after inclusion in Carbopol gel as it was already reported in literature [30,31]. This effect is still controversial; some studies showed a slower release of the encapsulant but other described the same profile after inclusion in a semi-solid dosage form [32]. As a representative example, a very recent work described the preparation of ethosomes with Achillea millefolium L. extract. In the permeation study, ethosomes alone or after inclusion of Carbopol had the same behavior. Thus, further studies should be done with aim to verify this hypothesis. 

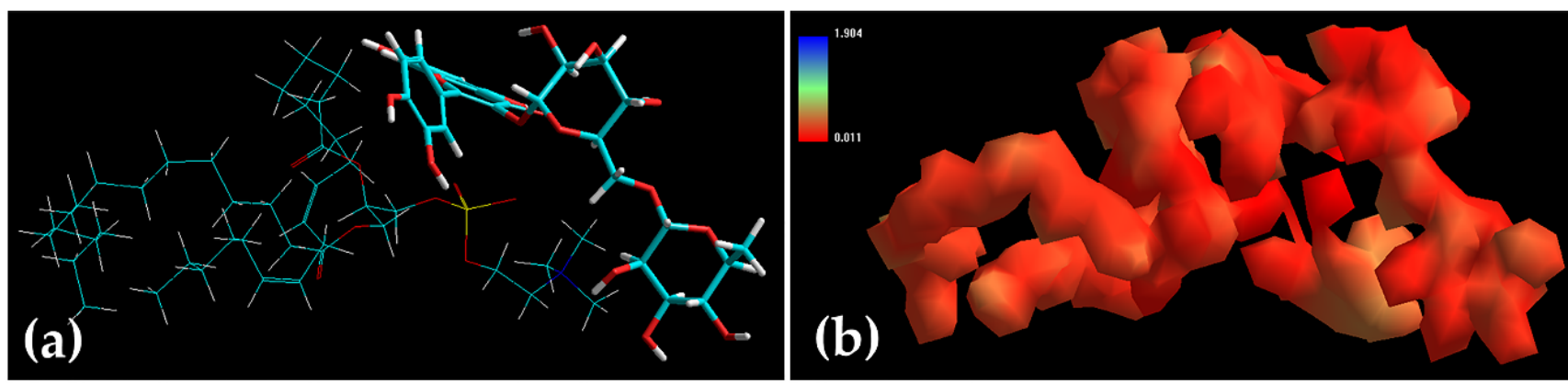

Figure 6. Representation of (a) geometrical preferences (b) electrostatic molecular graph after molecular mechanics simulations in vacuum $(\mathbf{a}, \mathbf{b})$ SPC-Rutin [Colour code for elements: $\mathrm{C}=$ cyan; $\mathrm{H}=$ white; $\mathrm{O}=$ red; $\mathrm{N}=$ blue]. Rutin: tube rendering; SPC: stick rendering.

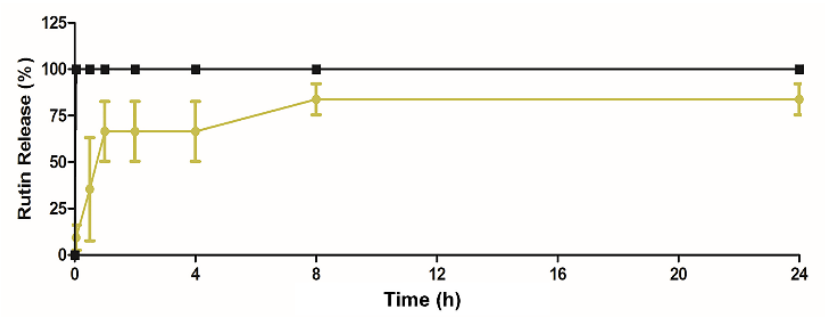

(a)

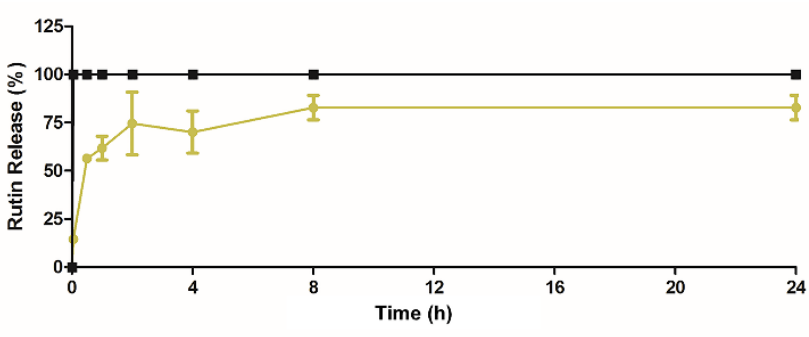

(b)

Figure 7. Percentage of rutin release free extract (black line) and extract-loaded ethosomes (yellow line), (a) in PBS pH 5.5, (b) in PBS pH 7.4.

\subsection{In Vitro Collagenase Inhibition Activity of Extract after Encapsulation}

The results obtained for the in vitro collagenase inhibition activity are showed in Figure 8 . The free extract $(93.57 \pm 0.61 \%)$ presented higher Coll inhibition activity the positive control $(84.36 \pm 0.91 \%)$. At equivalent concentration of the extract, extract-loaded ethosomes had the highest Coll inhibition activity $(99.67 \pm 0.09 \%)$.

This enzyme is generally involved in some skin diseases or disorders, being associated with the degradation of the collagen-rich extracellular matrix (ECM). Furthermore, there is a relationship between Coll-assisted ECM breakdown and tumor invasion [5]. The inhibition of this enzyme can prevent skin disorders or contribute for the treatment of these diseases. Among the phytocompounds previously identified in this extract, this inhibition can be related to the presence of naringenin [33]. This value was higher than some values described in previous studies. As an example, Zofia et al. tested different extracts in terms of Coll inhibition. Inhibition ranged between 10-40\% to Meum athamanticum L., less than $30 \%$ to Centella asiatica L. and varied between 20-75\% to Aegopodium podagraria L. [34].

\subsection{Preliminary In Vitro Safety Assessment of Extract in Ethosomes}

One important parameter in any formulation development is the safety [4]. Cell viability of HaCaT cells was performed for free extract as well as empty and extract-loaded ethosomes. The tested concentrations ranged from 8.13 to $130.00 \mu \mathrm{g}$ of rutin $/ \mathrm{mL}$, and results are depicted in Figure 9. A dose-dependent effect for free extract and loaded ethosomes was observed but this tendency was not observed for empty ethosomes. This reduction of cell viability observed in the ethosomes (empty or loaded) is possibly due to the presence of ethanol, which was not present in the extract. Besides the presence of ethanol, the ethosomes sizes by itself can be another possible reason, since they can act as physical barriers and thus interfere with cell growth. This observation is already well documented in several previous studies. 
A wide number of published works have stated that ethosomes are safe to be applied in humans and animals, presenting an excellent skin tolerability [35]. In fact, SPC presents a very high tolerability and biocompatibility [36]. In terms of in vitro scenario, keratinocyte (HaCat) cells represent $95 \%$ of epidermal cells [4,37], being more sensible than skin by itself in a real scenario $[4,38]$. Thus, in principle, there should be no concerns in terms of its application in humans as further section confirmed it.

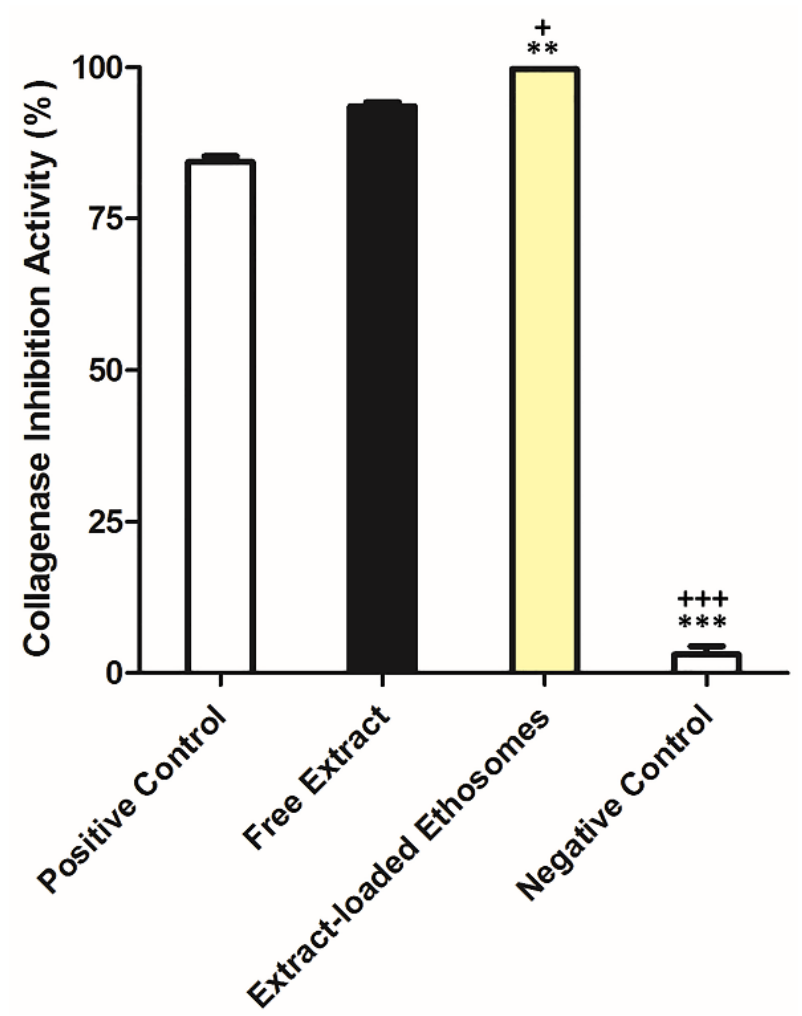

Figure 8. Coll inhibition activity of samples $\left(1 \mathrm{mg}\right.$ of sample $/ \mathrm{mL}$, mean \pm S.D., $n=3,{ }^{* *} p<0.01$ and ${ }^{* * *} p<0.001$, when compared to epigallocatechin gallate (EGCG, positive control-250 $\mu \mathrm{M}$ ) and $+p<0.05$ and $+++p<0.001$, when compared to free extract).

\subsection{Preliminary Stability Test of Semi-Solid Formulation with Free Extract and Ethosomes 2.9.1. Heating and Cooling Testing}

The organoleptic characteristics, $\mathrm{pH}$ and viscosity of each sample were evaluated over one week for heating and cooling tests, with analyses in four different times (immediately after the incorporation of the ethosomes into the gels, on the second, fourth and last day). Samples of gel with extract (Gel + E), gel with empty ethosomes (Gel + Etho) and extractloaded ethosomes (Gel + E-Etho) were compared to the gel (Carbopol ${ }^{\circledR} 940$ as control). This study reports for the first time that all these combinations were studied by diverse parameters and for different assays over time.

Concerning the Carbopol ${ }^{\circledR}$ 940, no phase separation (PS) was observed over time, after inclusion of extract, empty ethosomes and loaded ethosomes. The organoleptic characteristics did not change over time, with maintenance of similar colour for each sample. The $\mathrm{pH}$ values were registered for each sample, and a stable $\mathrm{pH}$ was verified for all samples, with slight variations (1.04 maximum) over time. These small changes of $\mathrm{pH}$ did not have any impact on the consistency of the gel, which is in conformity with the results reported by Islam et al. [39]. Viscosity is another main parameter of a potential semi-solid formulation for topical use. This parameter was measured for all samples over the time and the values are registered in Table 2. A decrease of viscosity over time was noticed. The comparison between the gel (control) and the $\mathrm{Gel}+\mathrm{E}$ revealed a statistical difference of $p<0.001$ on day 0 and 4 , but for the other time-points no difference was observed. The 
data suggested that the addition of extract led to an initial increase of viscosity, but after the second day, a decrease of the value of this parameter was registered, and this tendency was maintained over time. Concerning the samples of empty and extract-loaded ethosomes, it was verified a decrease of viscosity, which was maintained over time. This event can be a consequence of the addition of ethosomes in a solution. Regarding the free extract, it was included in gel in powder.

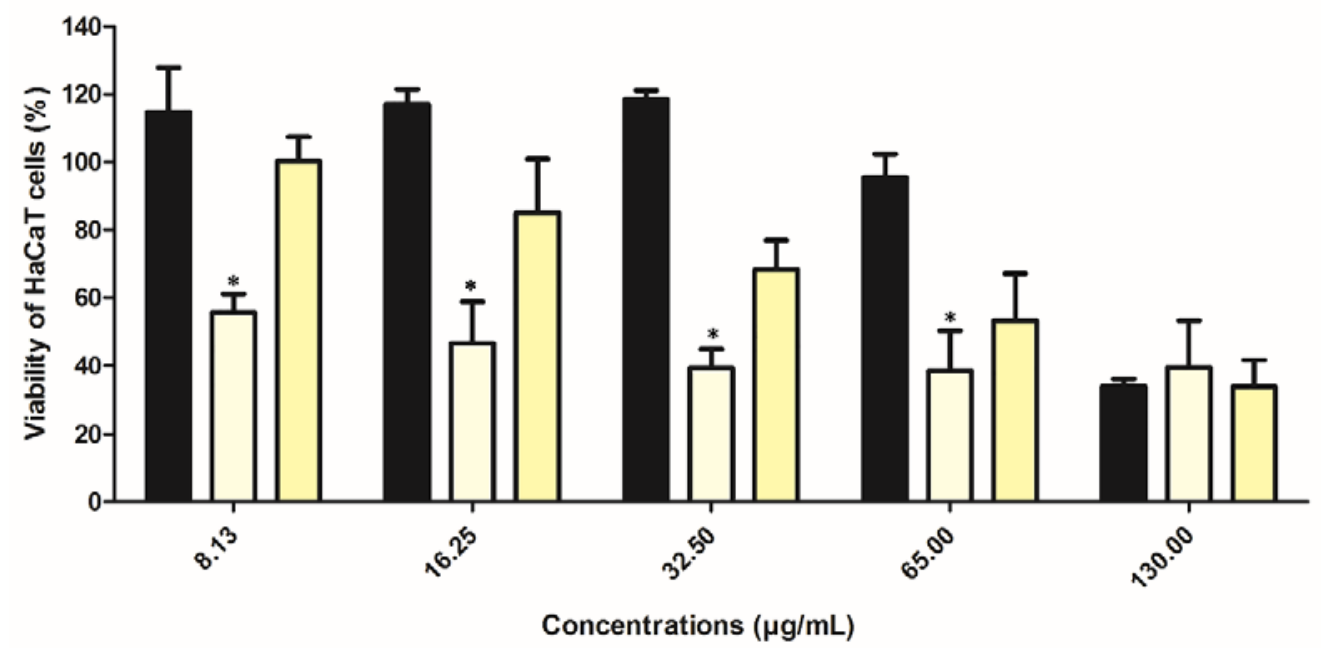

Figure 9. Cell viability (\%) of HaCaT following $48 \mathrm{~h}$ incubation of free extract (black columns), empty (light yellow columns) and extract-loaded ethosomes (dark yellow columns). Tested concentration ranged from 8-130 $\mu \mathrm{g}$ of rutin $/ \mathrm{mL}\left(\%\right.$, mean \pm S.D.; $n=6$; ${ }^{*} p<0.05$, when compared with free extract). Empty ethosomes were used at equivalent concentration of loaded ethosomes.

\subsubsection{Centrifugation Stress of Semi-Solid Formulation with Free Extract and Ethosomes}

The results of the organoleptic characteristics showed a normal appearance before and after centrifugation for all the samples. The $\mathrm{pH}$ values after the centrifugation ranged between 5.39-7.00, for Carbopol gel. In general, the samples presented similar $\mathrm{pH}$ before and after the centrifugation. Concerning viscosity, it was observed a decrease after centrifugation as can be seen in Table 2. Results suggested that for all samples, the addition of extract and ethosomes (empty or loaded) decreased the viscosity of the gel after centrifugation.

\subsection{Accelerated Stability of Semi-Solid Formulation with Free Extract and Ethosomes 2.10.1. Tests Cycles of Heating and Cooling}

Organoleptic characteristics observations revealed a normal appearance over time for all samples. The addition of extract into the gel decreases the $\mathrm{pH}$ of the gel and this behavior was maintained over the assay. On the other hand, the Gel + E-Etho led to an increase of $\mathrm{pH}$ value in the first moment and that was maintain until the end of assay. In terms of viscosity, samples of gel (control) and Gel + E presented a decrease at the end of the study. On the contrary, the sample of Gel + E-Etho presented a slight increase of viscosity over time and with the cycles of heating and cooling. Thus, concerning to viscosity this assay suggests that these samples present some vulnerability with the exposition to different temperature exposition. 


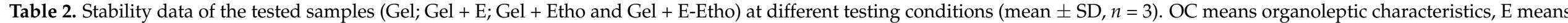
extract, Etho means ethosomes and E-Etho means extract-loaded ethosomes (N-normal, $\mathrm{AC}^{*}$ at $40 \pm 2{ }^{\circ} \mathrm{C}$ ).

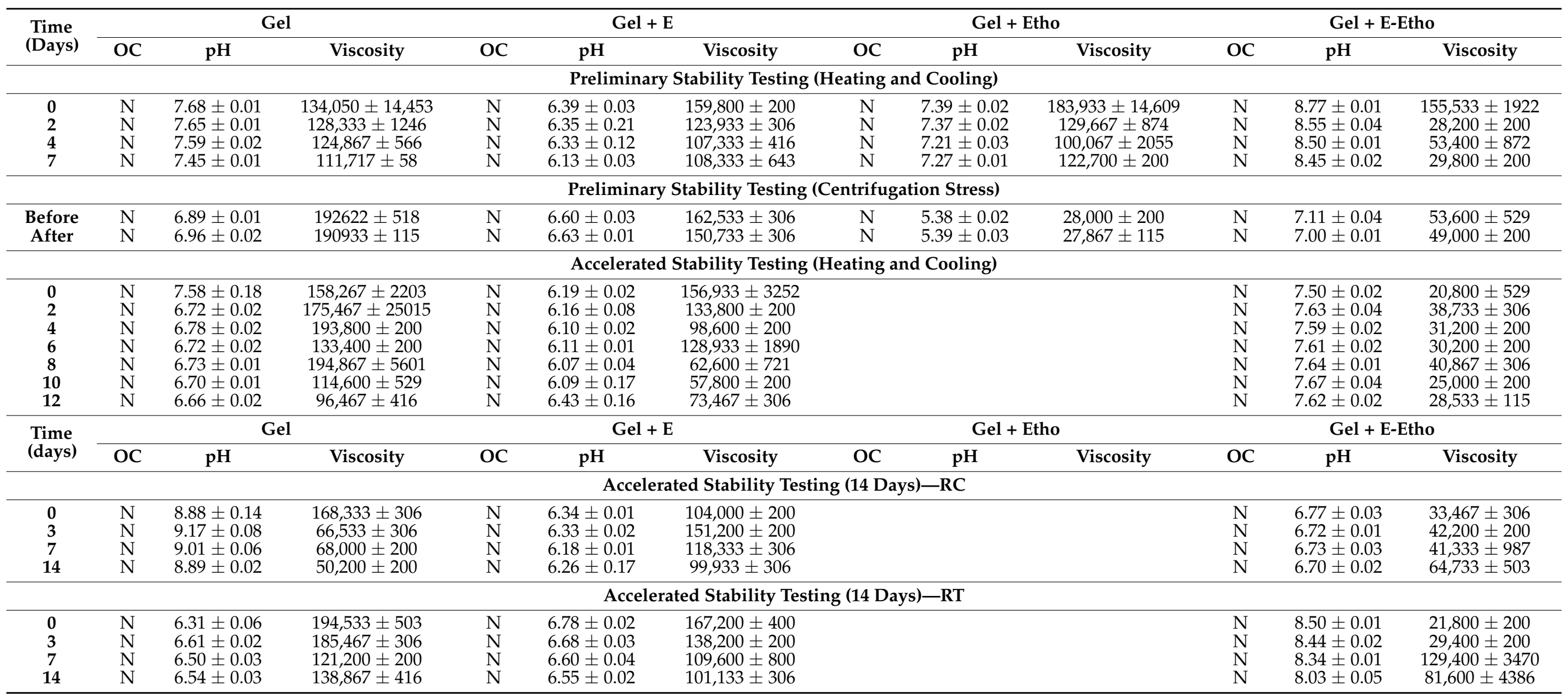


Table 2. Cont.

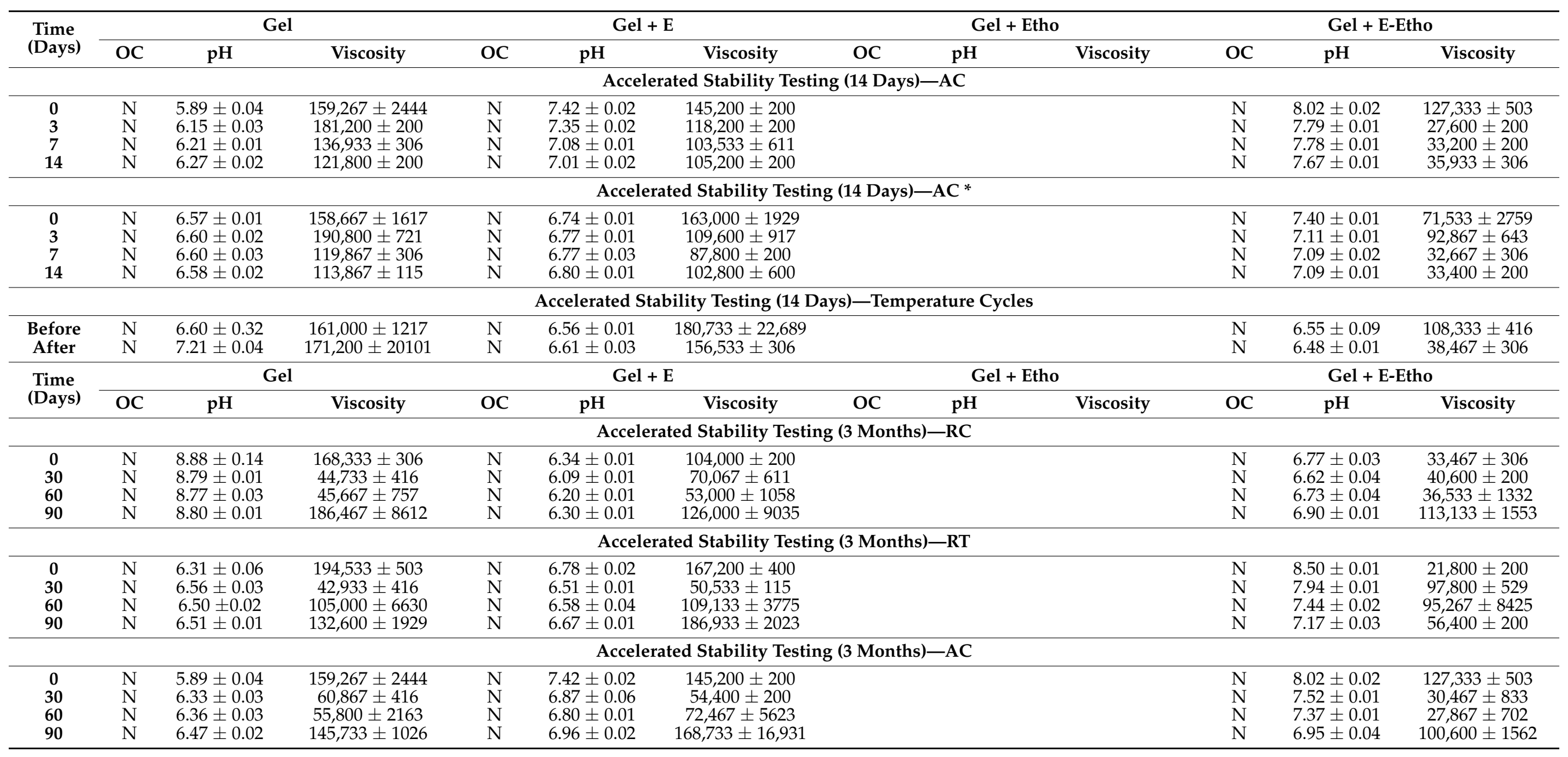




\subsubsection{Stability Test over 14 Days}

Organoleptic characteristics observations revealed a normal appearance over time for all samples under the different exposition temperatures. The addition of extract and extract-loaded ethosomes led to a slight decrease of the $\mathrm{pH}$ value that was kept over the assay, which suggest a stability of the samples under RC. Concerning the RT, the addition of extract or extract-loaded ethosomes increased the $\mathrm{pH}$ value and this difference was maintained over time. At AC, the addition of extract and extract-loaded ethosomes increased the $\mathrm{pH}$ value and this difference was also kept over time. The influence of temperature in the $\mathrm{pH}$ of the gel was evident, like previous study demonstrated [40]. The viscosity was measured for all samples in Carbopol ${ }^{\circledR} 940$ gel; it was observed an increase of viscosity over time at RC and RT for Gel + E-Etho but a decrease when exposed to AC and $\mathrm{AC}^{*}$, suggesting a direct correlation with the temperature to the Gel $+\mathrm{E}$. Nevertheless, no correlation was noticed to the Gel (control) and to Gel + E-Etho.

\subsubsection{Temperature Cycles}

The temperature cycles have no interference with organoleptic parameters and $\mathrm{pH}$ values, but regarding the viscosity, it was verified a decrease of values at the end of assay, that was more evident for the Gel + E-Etho. With the increase of temperature, the molecular vibrations might have also increase, changing polymer entanglement [32]. The change can be also due to the syneresis of the sample by itself, presence of ethanol and other compounds from the loaded ethosomes. This behavior was already reported in previous studies described in the literature [41,42].

\subsection{Stability over Three Months}

Organoleptic characteristics observations were registered over three months, every month, under three different temperatures (RC, RT and AC). The results did not reveal any change. The results for $\mathrm{pH}$ showed a decrease of difference over time with the increase of temperature for some of the samples, probably due to the release of some phytocompounds of the extract entrapped into the ethosomes. Regarding the viscosity, this parameter changed in the presence of extract, ethosomes, the presence of both and with temperature. This variation was already observed in previous studies. As an example, Dave et al. developed several ethosomes with gel formulations, but the most similar formula with this study revealed a viscosity of $7063 \pm 2.8 \mathrm{cP}$ [43]. Another example revealed that the addition of ethosomes in Carbopol gel affects its flow and viscoelastic behavior [44]. These authors suggested that the increase of temperature led to a decrease of viscosity, a consequence of the loosing of polymer entanglement at higher temperatures.

\subsection{Rheology of Semi-Solid Formulation with Free Extract and Ethosomes}

The rheology is important to characterize the stability of samples as well as to develop consumer acceptable final products [45]. This parameter allows to understand the rheological nature of the formulation, to perform studies of quality control of the effect of parameters like formulation, storage time and temperature on the quality of the formulation and to assess a product with regard to actual usage, such as spreading and adherence to the skin and removal from a tube or a jar. Profiles of all samples are presented in Figure 10. The results suggest that these samples present a shear thinning pseudoplastic behavior, which is according to the literature [46]. All tested samples consisted of hydrogels that are classified as non-Newtonian systems, exhibiting a non-linear relationship between stress and shear rate.

\subsection{Texture of Semi-Solid Formulation with Free Extract and Ethosomes}

It is generally accepted that the ideal characteristics of a fine semi-solid formulation for a better consumer acceptance are a good skin spread ability, an easy removal of product from the package and a good skin adhesion [47]. So, the aim of this study was to evaluate the textural properties of the different formulations concerning the physical gel 
structure [48]. The samples were analyzed in triplicate and the maximum peak force of displacement, also named hardness $\left(\mathrm{F}_{\max }, \mathrm{N}\right)$ and area of the peak $(\mathrm{AUC}, \mathrm{N} / \mathrm{s})$ are displayed in Figure 11. It was observed that the Gel + E seems to be more adhesive than the Gel + E-Etho, probably due to the presence of ethanol and dilution after ethosomes inclusion.

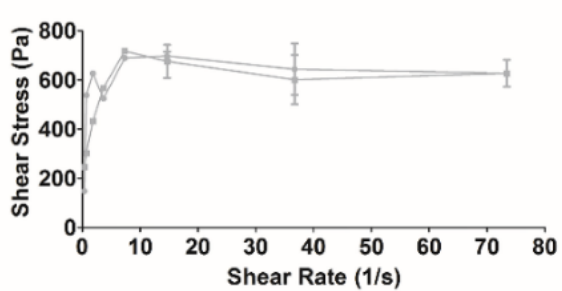

(a)

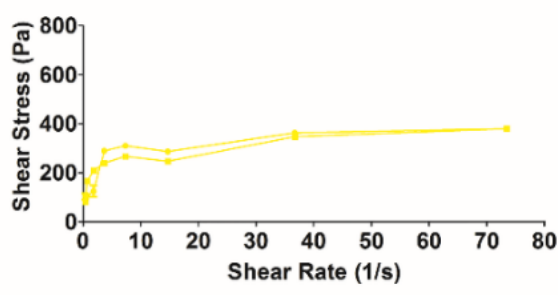

(c)

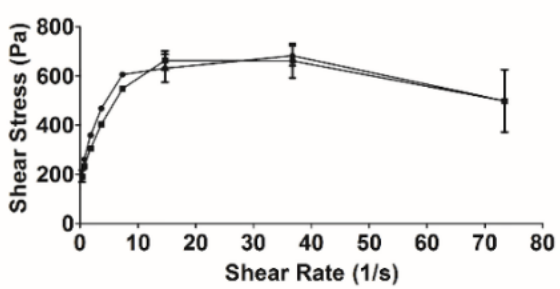

(b)

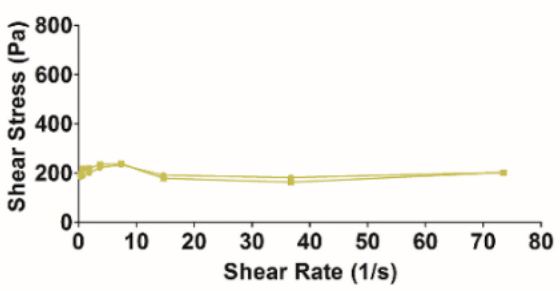

(d)

Figure 10. Rheology profile of samples $(\bullet)$ when increase the speed and $(\boldsymbol{\bullet})$ when decrease the speed (a) Gel (control), (b) Gel + E, (c) Gel + Etho, and (d) Gel + E-Etho (mean \pm S.D.; $n=3$ ).

\subsection{Skin Compatibility Test of Semi-Solid Formulation with Free Extract and Ethosomes}

The obtained results are presented in Table 3. Both samples showed very good skin compatibility. No reaction was detected for both samples in all the volunteers, confirming the safety of this formulation. The decrease of adhesion of the Gel + E-Etho observed in the texture analysis suggests that this change did not have any impact after topically delivered. Other properties are also important to achieve a suitable and effective topical delivery, such as the thixotropic properties and spreadability of the gel.

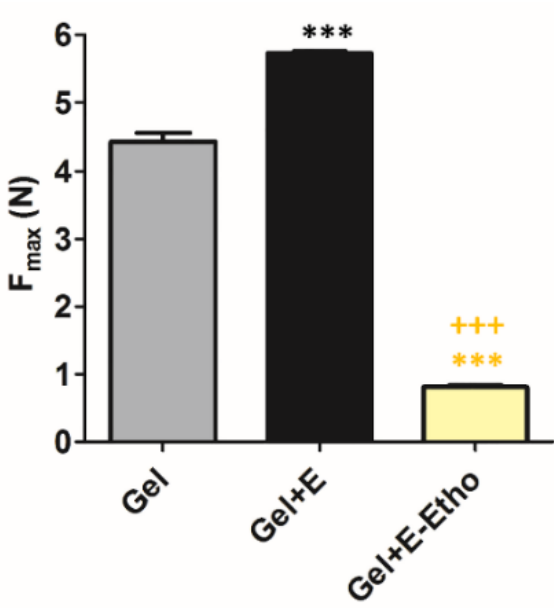

(a)

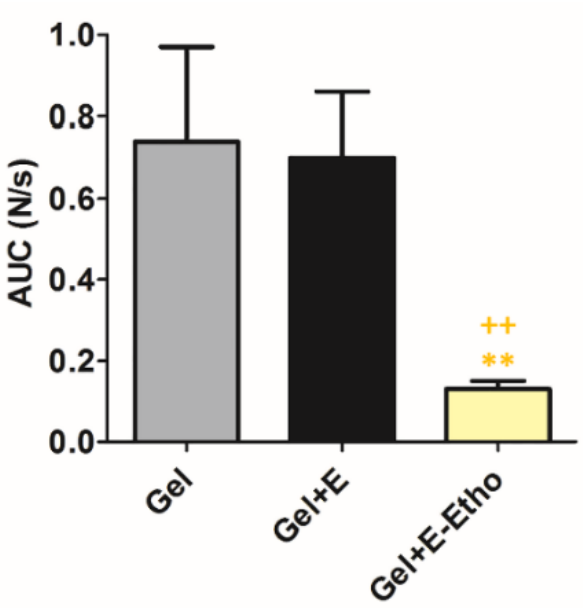

(b)

Figure 11. The (a) peak force of displacement $\left(F_{\max }, N\right)$ and the $(\mathbf{b})$ area of the peak (AUC, N/s) obtained from the force versus time curves. The results are presented regarding the mean \pm S.D.; $n=3\left({ }^{* *} p<0.01\right.$ and ${ }^{* *} p<0.001$ when compared with gel (control); ${ }^{++} p<0.01$ and $^{+++} p<0.001$, when compared with Gel + E). 
Table 3. Skin compatibility test for Gel $+\mathrm{E}$ and Gel + E-Etho ( $n=6$ each group, mean \pm S.D.).

\begin{tabular}{ccccc}
\hline Samples & $\begin{array}{c}\text { Control Time after } \\
\text { Patch Removal }\end{array}$ & $\begin{array}{c}\text { Reactive } \\
\text { Subjects }(\boldsymbol{n})\end{array}$ & $\begin{array}{c}\text { Types of } \\
\text { Reaction }\end{array}$ & $\begin{array}{c}\text { Mean Daily Irritation } \\
\text { Score (Mdis) }\end{array}$ \\
\hline Gel + E & $15 \mathrm{~min}$ & 0 & None & $0 \pm 0$ \\
& $24 \mathrm{~h}$ & 0 & None & $0 \pm 0$ \\
\hline Gel + E-Etho & $48 \mathrm{~h}$ & 0 & None & $0 \pm 0$ \\
& $15 \mathrm{~min}$ & 0 & None & $0 \pm 0$ \\
& $24 \mathrm{~h}$ & 0 & None & $0 \pm 0$ \\
& $48 \mathrm{~h}$ & 0 & None & $0 \pm 0$ \\
\hline
\end{tabular}

\section{Materials and Methods}

\subsection{Materials}

\subsubsection{Plant Material}

S. nigra L. flowers (elderflowers) were supplied by Régiefrutas-Cooperativa Agrícola de Interesse Público Távora-Varosa, CIPRL, collected from commercial crops at Tarouca, Beira

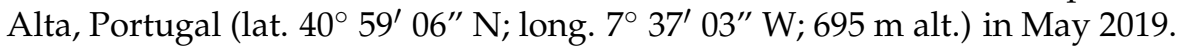

\subsubsection{Chemicals}

Phosphatidylcholine (L- $\alpha$-Phosphatidylcholine, also named soybean hosphatidylcholine, SPC) was supplied by Sigma Aldrich (St. Louis, MO, USA). Oleic Acid was acquired by Fluka Chemika (Buchs, Switzerland). Coll from Clostridium histolyticum type IA, Dulbecco's Modified Eagle's Medium-high glucose (DMEM), quercetin, thiazolyl blue tetrazolium bromide (MTT), Span $20^{\circledR}$, Nile Blue A and ascorbic acid were supplied by Sigma Aldrich (Steinheim, Germany). Fetal bovine serum (FBS) purchased from Biowest (Riverside, CA, USA). L-Glutamine was supplied by Lonza (Leuven, Belgium). Rutin was acquired from Extrasynthese (Genay, France). Methanol was purchased from António M. S. Cruz (Amadora, Portugal) and sodium chloride $(\mathrm{NaCl})$ from José M. Vaz Pereira (Benavente, Portugal). Epigallocatechingallate (EGCG), N-[3-furyl-acryloyl]-Leu-Gly-Pro-Ala (FALGPA) were purchased from Panreac (Barcelona, Spain). Tricine buffer was acquired by VWR (Leuven, Belgium). Carbopol $940^{\circledR}$ was purchased from Fagron (Barcelona, Spain). Folin reagent was supplied by Merck (Darmstadt, Germany). High performance liquid chromatography (HPLC) grade acetonitrile and formic acid were obtained from Chem-Lab $\mathrm{NV}$ (Zedelgem, Belgium). Milli-Q water $\left(18.2 \mathrm{M} \Omega \mathrm{cm}^{-1}\right.$ resistivity) was obtained from a Millipore-Direct Q3 UV system (Millipore ${ }^{\circledR}$, Burlington, MA, USA). All other chemicals were of analytical grade.

\subsubsection{Cell Lines}

The HaCaT cell line was supplied by Cell-Line-Service (cat: 300493, Eppelheim, Germany).

\subsection{Methods}

\subsubsection{Extraction}

The extract was obtained from fresh elderflowers, using methanol as solvent through ultrasonication method (Sonorex Super RK $510 \mathrm{H}$; Bandelin, Berlin, Germany) for $1 \mathrm{~h}$. The procedure was repeated three times until complete extraction $[4,5,49]$. The extract was then filtered, and the methanol was removed by rotary evaporation (VV2000 rotary evaporator from Heidolph, Apeldoorn, The Netherlands).

\subsubsection{Ethosomes Preparation Method}

To produce ethosomes, $2 \%$ of SPC $(w / v), 40 \%$ of ethanol $(v / v)$ and $58 \%$ of MilliQ water $(v / v)$ were used. Ethosomes then were centrifuged at $10,460 \times g$ (Centrifuge, Sigma Laborzentrifugen, Osterode am Harz, Germany) for $10 \mathrm{~min}$ at room temperature (RT) and then resuspended in MilliQ water. For the extract-loaded ethosomes, the same method was performed, and the amount of extract used was according to the proportion 1:1, w/w, 
lipid:extract. Empty and extract-loaded ethosomes were stored at $4 \pm 2{ }^{\circ} \mathrm{C}$-refrigeration conditions (RC). The ethosomes stored at these conditions were further used in all the assays.

\subsubsection{Lipid Quantification}

The lipid content of vesicles was determined using the modified colorimetric method described by Rouser et al. [50,51]. Briefly, the samples (in triplicate) with an amount of phosphate between 20 and $80 \mathrm{nmol}$ (sample volume below $100 \mu \mathrm{L}$ ) were cooled and after that $0.3 \mathrm{~mL}$ of perchloric acid (70-72\%) was added. Furthermore, all tubes were heated at $180{ }^{\circ} \mathrm{C}$ for $45 \mathrm{~min}$, in order to convert all the organic lipid phosphate to its inorganic form and the samples were cooled to RT. Subsequently, $1.0 \mathrm{~mL}$ of $\mathrm{H}_{2} \mathrm{O}$ and $0.4 \mathrm{~mL}$ of hexa-ammonium heptamolybdate solution $[1.25 \%(w / v)]$ followed by $0.4 \mathrm{~mL}$ of ascorbic acid solution $[5 \%(w / v)]$ were added. It was obtained a blue color solution due to the reduction of ascorbic acid over the heating process. In the end of method, the absorbance of all samples was recorded at $797 \mathrm{~nm}$ ) in a UV-mini 1240 spectrophotometer (Shimadzu, Kyoto, Japan) [51]. In parallel, a calibration curve was also prepared with amounts of phosphate ranging from 20 and $80 \mu \mathrm{mol} /$ tube, also in triplicate. All tubes were heated $\left(180{ }^{\circ} \mathrm{C}\right)$ in a heating block until dryness.

\subsubsection{Physical Characterization of Ethosomes: Size, Surface Charge and $\mathrm{pH}$}

Mean size, PdI, zeta potential and $\mathrm{pH}$ of empty and extract-loaded ethosomes were evaluated for up to 12 months [52]. Zeta potential of the ethosomes was measured in diluted $\mathrm{NaCl}(0.1 \mathrm{M})$ solution $(1: 10, v / v)$. The size, $\mathrm{PdI}$ and zeta potential were measured in diluted samples $(1: 16, v / v)$ by DLS, using a Malvern Zetasizer Nano-S and Nano-Z (Malvern Instruments, Worcestershire, UK). Results were expressed as mean of measurements in triplicate $(n=3)$. Stability study at different temperature was performed using three different temperatures $\left(4 \pm 2{ }^{\circ} \mathrm{C}-\mathrm{RC}, 25 \pm 5{ }^{\circ} \mathrm{C}-\mathrm{RT}\right.$ and $\left.40 \pm 2{ }^{\circ} \mathrm{C}-\mathrm{AC}\right)$. Results were expressed as the mean \pm S.D. $(n=3)$. The $\mathrm{pH}$ of the obtained suspension of ethosomes was measured using a pH electrode meter (827 pH Lab, Metrohm, Herisau, Switzerland), calibrated every day of measurements, with buffer solutions $\mathrm{pH} 4.00 \pm 0.02$ and $7.00 \pm 0.02$ $\left(20{ }^{\circ} \mathrm{C}\right)$ ST (Panreac).

3.2.5. Histochemical Characterization of the Lipidic Constitution of Ethosomes and Study of their Morphology

The lipidic constitution of ethosomes was histochemically demonstrated by Nile blue A, a stain used for detection of acidic and neutral lipids [53]. Microscope slides were prepared with a drop of the vesicular suspension, previously stained with an aqueous solution of $0.1 \%$ Nile blue A. Observations were carried out in bright field and in fluorescence with an BX51 light microscope (Olympus, Tokyo, Japan) equipped with a Nomarski and an epifluorescence condenser. For fluorescence, a filter set for green light with excitation at 535/30 $\mathrm{nm}$ and emission at $580 \mathrm{~nm}$ was used. Images were recorded digitally.

The morphological characteristics of the particles were investigated by scanning, transmission and atomic force microscopy techniques (SEM, TEM and AFM, respectively). For SEM, aliquots $(20 \mu \mathrm{L})$ of the vesicular suspensions were carefully dispersed on round glass coverslips coated with poly L-lysine and previously attached to the microscope stubs. The samples, after dried in a desiccator, were sputter-coating with gold and observed with a 5200LV scanning electron microscope (JEOL Ltd., Tokyo, Japan) at an accelerating voltage of $20 \mathrm{kV}$. Images were recorded digitally. For TEM, aliquots $(10 \mu \mathrm{L})$ of NPs suspensions were placed on Formvar/carbon coated grids and the excess solution was removed with a filter paper. Then, the material was negatively stained with $1 \%$ of uranyl acetate and left in room conditions for air-drying. Observations were carried out on a 1200EX transmission electron microscope (JEOL Ltd., Tokyo, Japan) operating at $80 \mathrm{kV}$ and images were recorded digitally.

For the atomic force microscopy (AFM) analysis, the samples were centrifuged at $7378 \times g$ (Sigma Laborzentrifugen, Osterode am Harz, Germany) for 10 and 20 min, for empty and extract-loaded vesicles, respectively, followed by resuspension in water (in half 
of the previous volume) [54]. AFM uses a diluted sample, 1:2 without any pre-treatment. A freshly cleaved mica surface was used to place a drop $(\approx 40 \mu \mathrm{L}$ of sample), being allowed to adsorb for around $30 \mathrm{~min}$ [54]. After drying using a stream of N2, samples were analyzed in intermittent mode (Multimode $8 \mathrm{HR}$ Microscope, produced by Bruker, Billerica, MA, USA) [54]. Images were acquired in ambient conditions $\left(\approx 21^{\circ} \mathrm{C}\right)$, through the use of etched silicon tips with a resonance frequency of around $320 \mathrm{kHz}$ (NCHV, Bruker), at a scan rate near to $1.3 \mathrm{~Hz}$ [54]. All images were recorded digitally.

\subsubsection{Entrapment Capacity of Extract in Ethosomes}

To determine the EC of the elderflower extract, the samples were analyzed by HPLCMS/MS aiming at quantifying rutin, the major compound of the methanolic extract. The Waters ${ }^{\circledR}$ Alliance 2695 HPLC system (Waters ${ }^{\circledR}$, Dublin, Ireland) equipped with an autosampler, quaternary pumps, column furnace, and a diode-array detector (DAD) Waters 996 DAD $\left(\right.$ Waters $\left.{ }^{\circledR}\right)$ was used to performer the assays. Chromatographic analyses were carried out using a LiChrospher ${ }^{\circledR} 100 \mathrm{RP}-18,5 \mu \mathrm{m}(250 \times 4 \mathrm{~mm})$ column at $35^{\circ} \mathrm{C}$. A mixture of formic acid $(0.5 \% v / v$ in ultrapure water) (eluent $\mathrm{A}$ ) and $0.5 \%$ formic acid in acetonitrile (eluent $\mathrm{B}$ ) at a flow rate of $0.3 \mathrm{~mL} / \mathrm{min}$, were used as a mobile phase. The initial conditions were maintained for $20 \mathrm{~min}$ as a re-equilibration step. The gradient was: $5 \% \mathrm{~B}$ (0-10 min), 15\% B (10-30 min), 20\% B (30-45 min), 20\% B (45-65 min), 54\% B (65-95 min), $63 \% \mathrm{~B}(65-110 \mathrm{~min})$, and 5\% B (110-115 min). The total running time was $135 \mathrm{~min}$ and the injection volume $20 \mu \mathrm{L}$. The HPLC system was coupled to a triple quadrupole mass spectrometer MicroMass Quattromicro ${ }^{\circledR}$ API (Waters ${ }^{\circledR}$, Dublin, Ireland) equipped with an electrospray ionization source (ESI).

MS/MS conditions were optimized for the identification and quantification of rutin. The electrospray ion source (ESI) was set to operate at $120^{\circ} \mathrm{C}$ in negative mode, using a capillary voltage of $2.5 \mathrm{kV}$, cone voltage of $45 \mathrm{~V}$ and collision energies of 32 , and $34 \mathrm{eV}$. High purity nitrogen was used as drying and as a nebulizing gas. The collision gas used was the ultra-high purity argon. Analyses were performed in multiple reaction monitoring mode $(\mathrm{MRM})$, selecting the one product ion with the highest signal as the monitored transitions for quantification (MRM1, $609.00>300.00$ ) and confirmation (MRM2, $609.00>271.00$ ) purposes. MassLynx Version 4.1 software (Waters) was used for instrument control, data acquisition, and data processing.

The $E C$ was determined by analyzing the rutin present in the supernatant-indirect method). EC was determined by the Equation (1):

$E C=\left(\frac{\text { Total amount }_{\text {major bioactive compound }}-\text { Amount }_{\text {free }} \text { major bioactive compound }}{\text { Total amount }}\right) \times 100$

\subsubsection{Rutin and Ethosomes Complex Simulation}

The reactional profile of extract and ethosomes system was assessed in silico via molecular mechanics simulations and the ensuing energetic-geometric stabilization provided an insight into the antioxidant potential of ethosomes. To analyze the mechanism governing the Coll potential of the ethosomes, energetic and geometrical stabilization of the druglipid molecular complexes were conducted using atomistic simulations (HyperChemLite Molecular Modelling Software, Hypercube Inc., Gainesville, FL, USA). The structures of SPC and rutin were generated as natural bond angles. The individual molecules and the biomolecular complexes (SPC-rutin) were energy minimized and optimized employing MM3 Force Field algorithm which was further accompanied by a Polak-Ribiere Conjugate Gradient method until an RMS gradient of $0.001 \mathrm{kcal} / \mathrm{mol}$ was achieved [55,56].

\subsubsection{In Vitro Release Studies}

Extract-loaded ethosomes were previously lyophilized over $24 \mathrm{~h}$ at $-50{ }^{\circ} \mathrm{C}$ (freezedryer model, Edwards, Edwards, CO, USA). Afterwards, they were solubilized into phosphate buffer solution (PBS) (USP41) pH $5.5(10 \mathrm{~mL})$ to simulate human skin $\mathrm{pH}$ and stirred 
(200 rpm) at $32{ }^{\circ} \mathrm{C}$ in a multiplate stirring plate. Sink conditions were assured over the whole assay. Aliquots of the release medium were collected at appropriate time intervals (5 and $30 \mathrm{~min}, 1,2,4,8$ and $24 \mathrm{~h}$ ), and replaced immediately with fresh buffer. The same assay was performed in PBS at pH 7.4 (USP41). As reference, rutin was previously identified as the major flavonoid of the extract [5], therefore a standard calibration curve was performed with rutin solution in PBS buffer $\mathrm{pH} 5.5$ or 7.4, depending on the assay. Extract concentration at each time point was determined using HPLC-DAD- MS/MS.

HPLC-DAD-MS/MS assays were carried out on a Waters ${ }^{\circledR}$ Alliance 2695 HPLC system (Waters ${ }^{\circledR}$ ) coupled to a 2996 Photodiode Array Detector and a Micromass ${ }^{\circledR}$ Quattro Micro triple quadrupole (TQ) (Waters ${ }^{\circledR}$ ). These analyses were performed at $35^{\circ} \mathrm{C}$ on a LiChrospher ${ }^{\circledR} 100 \mathrm{RP}-18(250 \times 4 \mathrm{~mm}, 5 \mu \mathrm{m})$ column. The mobile phase used was the same as described in Section 3.2.6. The elution program consisted of $20 \%$ B (0-5 min), with increase to $90 \%$ B in $10 \mathrm{~min}, 90 \%$ B (15-20 min), and with a decrease to $20 \%$ B in $1 \mathrm{~min}$, and ultimately the initial conditions were maintained for $20 \mathrm{~min}$ as a re-equilibration step. Total run time was $40 \mathrm{~min}$ and the injection volume $10 \mu \mathrm{L}$. MS/MS conditions were already described in Section 3.2.6.

\subsubsection{In Vitro Collagenase Inhibition Activity}

The protocol used was already described in previous works $[4,5,57]$. This assay was performed in $50 \mathrm{mM}$ tricine buffer ( $\mathrm{pH}$ 7.5) enriched with $400 \mathrm{mM} \mathrm{NaCl}$, and $10 \mathrm{mM}$ $\mathrm{CaCl}_{2}$. The FALGPA (substrate) was dissolved in tricine buffer $(2 \mathrm{mM}$ ) whereas Coll from Clostridium histolyticum (EC.3.4.23.3) was dissolved in a buffer at an initial concentration of 0.8 Units/mL and according to the supplier's activity data. Negative controls were the respective sample solvent. The absorbance was measured at $405 \mathrm{~nm}$ after the substrate addition over 10 min using a microplate reader (Thermo Scientific Multiskan FC, Shanghai, China). The positive control (EGCG) was used at a concentration of $250 \mu \mathrm{M}$. This compound has been reported as being a strong inhibitor of collagen degradation [58]. The Coll inhibition (\%) was determined using the Equations (2) and (3):

$$
\begin{gathered}
\text { Velocity reaction of control or inhibitor }=\frac{\text { Corrected } A b s}{\text { time }(\mathrm{min})} \\
\text { Collagenase inhibition activity }(\%)=100-\left(\frac{100 \times \text { Velocity reaction of inhibitor }}{\text { Velocity reaction of control }}\right)
\end{gathered}
$$

For the Coll activity, the absorbance decrease was calculated using the Equation (2) for the velocity reaction of negative control $\left(\Delta \mathrm{Abs}_{405 \mathrm{~nm}} / \mathrm{min}\right)$ and after to determine the Coll inhibitions activity, it was used the Equation $(3)[4,5,57]$.

\subsubsection{In Vitro Safety Assessment}

The in vitro safety of the free extract, empty and extract-loaded ethosomes were evaluated using the MTT assay in the human keratinocyte cell line (HaCaT, cell line). These cells were seeded in 96-wells plate at a density of $5 \times 10^{4}$ cells $/ \mathrm{mL}$ in DMEM with high-glucose $(4500 \mathrm{mg} / \mathrm{L})$, supplemented with 10\% FBS, and $100 \mathrm{IU} / \mathrm{mL}$ of penicillin and $100 \mu \mathrm{g} / \mathrm{mL}$ streptomycin [(Pen/Strep, 1\%,v/v)], and allowed to grow for $24 \mathrm{~h}$ in a humidified chamber at $37^{\circ} \mathrm{C}$ in a $5 \% \mathrm{CO}_{2}$ atmosphere [59]. For this assay, the medium was removed and samples at concentrations ranging from 8.13-130.00 $\mu \mathrm{g}$ of rutin/mL (free extract and equivalent concentrations of extract into ethosomes, according to the results obtained for EC were prepared and added to HaCaT cells. After $48 \mathrm{~h}$, the samples were removed, and the cell monolayers were washed with PBS. Then, $50 \mu \mathrm{L}$ of MTT at $0.5 \mathrm{mg} / \mathrm{mL}$ was added to the cells and the plates were incubated for $4 \mathrm{~h}$ in a humidified chamber at $37{ }^{\circ} \mathrm{C}$ and $5 \% \mathrm{CO}_{2}$ atmosphere. After this incubation time, $100 \mu \mathrm{L}$ of DMSO 
was added to each well to solubilize the formazan crystals. The absorbance (Abs) was measured, and cell viability was calculated using the same Equation (4):

$$
\text { Cell Viability }(\%)=\frac{A b s_{t}}{A b s_{c}} \times 100
$$

where $A b s_{t}$ is the absorbance of the sample and $A b s_{c}$ the absorbance of the control.

\subsubsection{Inclusion of Extract-Loaded Ethosomes in a Semi-Solid Formulation}

Carbopol ${ }^{\circledR} 940$ gel was prepared based on previous literature with slight modifications [60]. Briefly, $500 \mathrm{mg}$ of Carbopol ${ }^{\circledR} 940$ was dispersed in water under stirring (400 rpm) until complete solubilization. Then, $0.2 \%$ of methyl 4 -hydroxybenzoate and $0.02 \%$ of propyl-4-hydroxybenzoate were added under constant stirring. Finally, $\mathrm{NaOH}$ was added to Carbopol (0.4 g of $\mathrm{NaOH}$ per gram of Carbopol) under magnetic stirring. This last reagent was responsible for the gelling effect.

The resultant Carbopol ${ }^{\circledR} 940$ gel was then characterized. A total of four different samples were tested: gel only (control); gel + Extract $(\mathrm{Gel}+\mathrm{E})$; gel + empty ethosomes (Gel + Etho) and gel + extract-loaded ethosomes (Gel + E-Etho), as schematic illustrated on the Figure 12. Incorporation of extract was performed according HPLC values (Section 3.2.6). Specifically, $1.5 \mathrm{mg}$ of extract was mixed with $1 \mathrm{~mL}$ of Carbopol gel, followed by vortexing $5 \mathrm{~s}$. Incorporation of ethosomes was performed by adding $2.34 \mathrm{~mL}$ of ethosomes suspension/mL of Gel to a tube, followed by same vortexing.

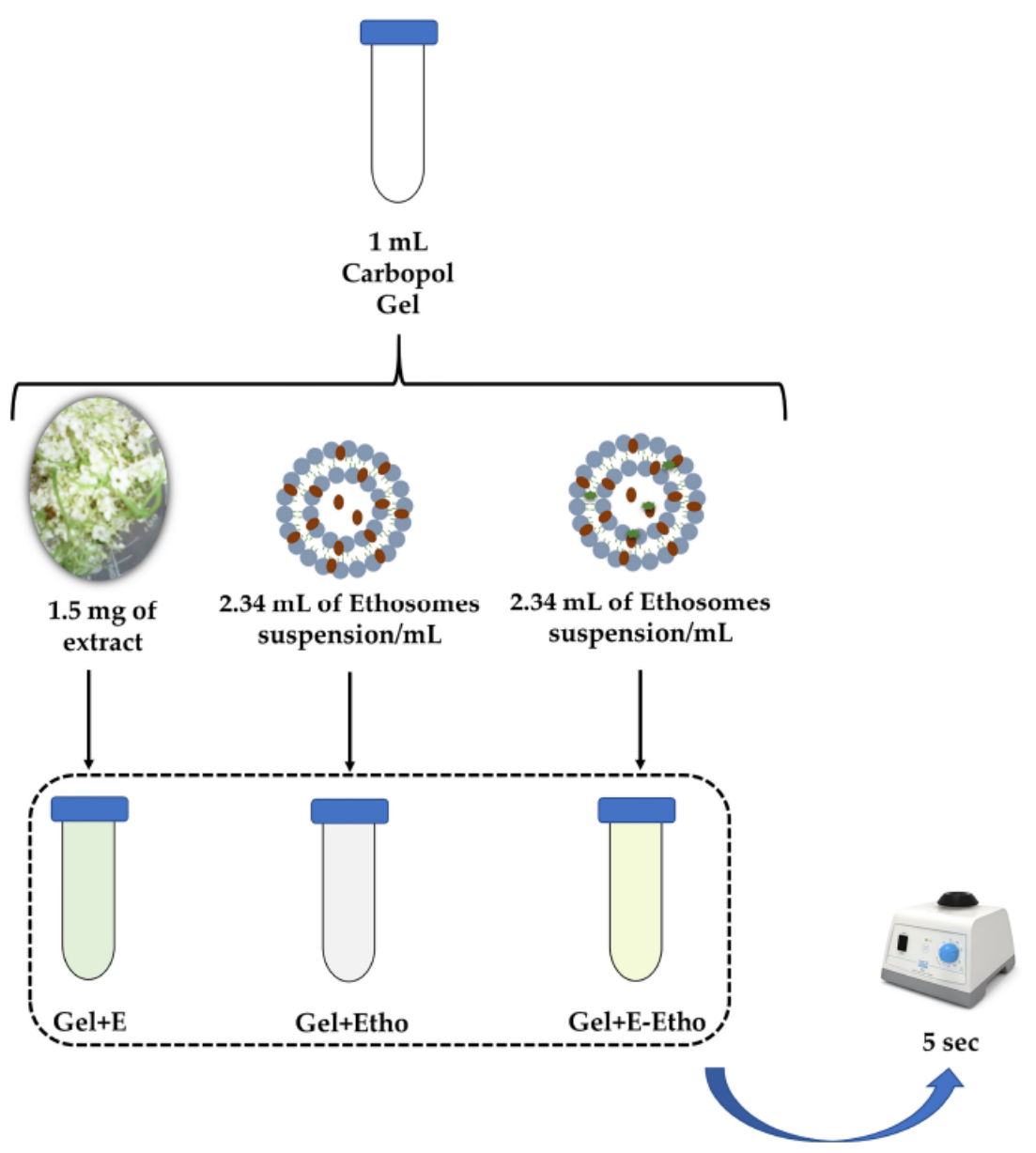

Figure 12. Schematic representation of inclusion of Extract-Loaded Ethosomes in a Semi-Solid Formulation. 
3.2.12. Characterization of the Semi-Solid Formulation for Skin Delivery of S. nigra Extract

- Organoleptic Characteristics

The obtained gels with and without ethosomes were characterized in terms of aspect (colour and homogeneity) and odor. The organoleptic characteristics were evaluated by direct observation of samples. When the physical appearance was maintained, the samples were classified as normal whereas they were classified as PS when a phase separation was observed.

- $\mathrm{pH}$ Measurement

Measurement of the $\mathrm{pH}$ was performed at $\mathrm{RT}$ in triplicate using potentiometer $(827 \mathrm{pH}$ Lab, Metrohm, Herisau, Switzerland). This equipment was daily calibrated with buffer solutions pH $4.00 \pm 0.02$ and $7.00 \pm 0.02\left(20^{\circ} \mathrm{C}\right)$ (Panreac).

- Viscosity Measurement

The viscosity was measured using a DV-I + Viscometer (Brookfield Engineering Labs. Inc., Middeborough, MA, USA) with the $\mathrm{n}^{\circ} 4$ needle and using a speed rate of $3 \mathrm{rpm}$.

- Preliminary Stability Assays of Semi-Solid Formulation with Free Extract and Ethosomes

The following tests were performed in all samples, i.e., with and without empty and extract-loaded ethosomes as previously reported by Reis et al. [61] and according to the International Guideline ICHQ1A (R2) [62]. The preliminary stability assays included the heating and cooling, as well as the centrifugation stress:

(1) Heating and Cooling

Samples were submitted to heat-freeze cycles $\left[25 \pm 2{ }^{\circ} \mathrm{C}\right.$ in an oven $(24 \mathrm{~h})$, then cooled to $-5 \pm 2{ }^{\circ} \mathrm{C}$ in a freezer $\left.(24 \mathrm{~h})\right]$, over one week. Frozen samples were allowed to melt and cool down to RT prior measurements. Samples were analyzed at 48, 96 and $168 \mathrm{~h}$ in terms of organoleptic characteristics, $\mathrm{pH}$ measurement and viscosity, as previously presented [61].

(2) Centrifugation Stress

This assay was adapted from Reis et al. (2015) [61]. Each sample (approximately 6 g) was exposed to a $50{ }^{\circ} \mathrm{C}$ water bath (Heidolph MR3001, Heidolph Instruments, Schwabach, Germany) and, subsequently, centrifuged at 1077 $\times g$ for 30 min (Beckman Gpr Refrigerated Centrifuge Rotor, Indianapolis, IN, USA). The parameters of organoleptic characteristics, $\mathrm{pH}$ measurement and viscosity, were verified before and after centrifugation.

- Accelerated Stability Assays of Semi-Solid Formulation with Free Extract and Ethosomes

The following tests were performed in empty and extract-loaded ethosomes as previously reported [61] and under Guideline ICHQ1A (R2) [62].

(1) Tests Cycles of Heating and Cooling

Samples were incubated at $45 \pm 2{ }^{\circ} \mathrm{C}$ in the oven and cooled in the freezer at $-10 \pm 2{ }^{\circ} \mathrm{C}$ (cycles of $24 \mathrm{~h}$ at each condition) for twelve days. Samples were analyzed every two days. This analysis included the evaluation of the parameters referred above (organoleptic characteristics, $\mathrm{pH}$ measurement and viscosity).

(2) Stability Test over 14 Days

Samples were exposed to three different settings: refrigerated conditions (RC, $\left.-5 \pm 2{ }^{\circ} \mathrm{C}\right)$; RT $\left(20 \pm 5^{\circ} \mathrm{C}\right)$, and accelerated conditions (AC, $50 \pm 2{ }^{\circ} \mathrm{C}$ and $\mathrm{AC}^{*}, 40 \pm 2{ }^{\circ} \mathrm{C}$ ) for 14 days. In this case, two different ovens were used to evaluate different conditions, one of them in regular or normal oven at $50 \pm 2{ }^{\circ} \mathrm{C}$, and the other one in a climatic chamber at $40 \pm 2{ }^{\circ} \mathrm{C}$. After 3,7 and 14 days, formulations were analyzed and the parameters, already mentioned evaluated. 


\section{(3) Temperature Cycles}

Samples were exposed to water bath at $40{ }^{\circ} \mathrm{C}$, with a controlled heating rate of $10{ }^{\circ} \mathrm{C} / 30 \mathrm{~min}$ of up to $80^{\circ} \mathrm{C}$. After returning to RT, the samples were analyzed in the same parameters than the previous tests.

- Stability over Three Months

Samples were exposed to three different settings: RC $\left(-5 \pm 2{ }^{\circ} \mathrm{C}\right)$; RT $\left(20 \pm 5^{\circ} \mathrm{C}\right)$, and AC $\left(50 \pm 2{ }^{\circ} \mathrm{C}\right)$ for 3 months. After 1, 2 and 3 months, formulations were analyzed and organoleptic characteristics, $\mathrm{pH}$ measurement and viscosity determined.

- Rheological Properties

The procedure was based on the method of Braden [63], with slight modifications. The same needle was used and the values of viscosity for different speeds starting with the lowest $(0.3 \mathrm{rpm})$ and gradually increasing the speed until $60 \mathrm{rpm}$.

- $\quad$ Texture Analysis

The texture of all samples was assessed by the TA.XT.plus (Texture Analyzer Stable Micro Systems, Surrey, UK). This assay was done using the following characteristics: pretest speed $(0.50 \mathrm{~mm} / \mathrm{s})$; test speed $(0.50 \mathrm{~mm} / \mathrm{s})$; post-test speed $(10.00 \mathrm{~mm} / \mathrm{s})$; applied force $(500.0 \mathrm{~g})$; return distance $(10.000 \mathrm{~mm})$; contact time (10.00 s); trigger type (automatic) and trigger force $(5.0 \mathrm{~g})$. The estimated mean areas under the force-time curve were calculated for each sample, in triplicate analysis.

\subsubsection{Human Skin's Compatibility Testing}

The skin's compatibility was performed by occlusive patch Finn Chamber ${ }^{\circledR}$ standard [64] with some modifications made by Mazulli et al. [65]. A group of 12 subjects ( $\mathrm{n}=6$ each group) with age between 18 to 70 years, female and male, with phototype (Fitzpatrick) I to IV and to all type of skin was randomized in two different groups: one group dosed with gel with extract and the other group dosed with gel with extract-loaded ethosomes. The goal of the present case was reached after a single application to the human skin. The tested samples were: the final formulation of Gel + E and Gel + E-Etho $(20 \mu \mathrm{L}$ each). The formulations were in contact with skin, under patch in the back, for $48 \pm 5 \mathrm{~h}$. The examination was carried out, visually under standard "daylight", before patching on first day and about $15 \mathrm{~min}$ (or more if some redness appeared after patch removal), then 24 and $48 \mathrm{~h}$ after patch removal. All the tests were made according to the Declaration of Helsinki and received the approval of the local Ethics Committee.

The mean daily irritation score (Mdis) was determined using Equation (5), where Idis represents the individual daily irritation score, which is obtained by the sum of the marks obtained for all the signs observed [66].

$$
\text { Mdis }=\frac{\sum \text { Idis }}{\text { number of valid cases }}
$$

\subsubsection{Statistical Analysis}

Results were expressed as mean \pm standard deviation (S.D.). The results concerning the biological assays were expressed as mean \pm standard error of the mean (S.E.M.). OneWay ANOVA for multiple comparisons was used to assess the significance of differences by Graph Prisma Version 5.03 (GraphPad Software, San Diego, CA, USA). Only it was considered the significant differences when $p<0.05$. Two-Way ANOVA for multiple comparisons between all samples. Concerning to the results of incorporation of the extractloaded ethosomes were expressed as mean \pm S.D. Statistical analysis was performed using Two-Way ANOVA for multiple comparisons between control and different formulations by Bonferroni test, using GraphPad Prism 5.03. Results were considered significantly different when $p<0.05$. 


\section{Conclusions}

Ethosomes demonstrated to be a good nanocarrier for the Sambucus nigra L. flower extract, regarding the high EC. In addition, these nanocarriers showed a high value of Coll inhibition. After the incorporation in Carbopol gel, these results suggested to be a stable gel over the time, in terms of organoleptic characteristics, $\mathrm{pH}$ and viscosity at different temperatures of storage. This formulation was also safe for humans and thus it can be considered a promising topical formulation, attracting a wide interest from cosmetic industry.

Supplementary Materials: The following are available online at https:/ /www.mdpi.com/article/10 $.3390 / \mathrm{ph} 14050467 / \mathrm{s} 1$, Figure S1. Chromatogram of methanolic elderflowers extract at $280 \mathrm{~nm}$.

Author Contributions: Conceptualization: C.P.R.; Formal analysis, A.H.M., I.P., H.M., A.B.-S., M.J.R., N.D., A.T.S., M.R.B., P.R., M.M.G., A.S.V., L.A., P.P., P.K., A.J.A. and C.P.R.; Funding acquisition, N.D., P.R., M.M.G., P.K., A.J.A. and C.P.R.; Investigation, A.H.M., I.P., H.M., A.B.-S., M.J.R., N.D., A.T.S., M.R.B., P.R., M.M.G., A.S.V., L.A., P.P., P.K., A.J.A. and C.P.R.; Methodology, C.P.R.; Project administration, C.P.R.; Supervision, A.J.A. and C.P.R.; Writing-original draft, A.H.M., I.P. and H.M.; Writing-review \& editing, N.D., M.M.G., A.S.V., L.A., P.P., P.K., A.J.A. and C.P.R. All authors have read and agreed to the published version of the manuscript.

Funding: Authors also gratefully acknowledge the Régiefrutas, iMed and Fundação para a Ciência e a Tecnologia (FCT) (UIDB/04138/2020, UIDB/00100/2020, UIDP/50017/2020+UIDB/50017/2020, COFAC/ILIND/CBIOS/1/2020 and CCMAR/Multi/04326/2019 project), Portugal 2020, Portuguese Mass Spectrometry Network (LISBOA-01-0145-FEDER-402-022125), FCT/MCTES for the financial support to CESAM (UIDP/50017/2020, UIDB/50017/2020), INTERFACE Programme (Innovation, Technology and Circular Economy Fund (FITEC) and iNOVA4Health-UIDB/04462/2020, a program financially also supported by FCT. A.T.S. also acknowledge FCT/Ministério da Educação e Ciência for the Individual Grant CEECIND/04801/2017.

Institutional Review Board Statement: The study was conducted according to the guidelines of the Declaration of Helsinki and approved by the Institutional Review Board (or Ethics Committee) of PhD trials, protocol code 15860121.C and 15860121.D and approved on 27 January 2021.

Informed Consent Statement: Informed consent was obtained from all subjects involved in the study.

Data Availability Statement: The data presented in this study are available on request from the corresponding author.

Acknowledgments: The authors are also grateful to Jacinta Pinho from iMED.Ulisboa, Faculty of Pharmacy, University of Lisboa (Lisbon, Portugal) and João Mota from Faculty of Pharmacy, University of Lisboa (Lisbon, Portugal), as well as Sheila Alves from Instituto de Biologia Experimental e Tecnológica (Oeiras, Portugal) in conducting some experiments.

Conflicts of Interest: The authors declare no conflict of interest. The funders had no role in the design of the study; in the collection, analyses, or interpretation of data; in the writing of the manuscript, or in the decision to publish the results.

\section{References}

1. Mota, A.H.; Santos-Rebelo, A.; Almeida, A.J.; Reis, C.P. Therapeutic Implications of Nanopharmaceuticals in Skin Delivery. In Nanopharmaceuticals: Principles and Applications; Yata, V.K., Ranjan, S., Dasgupta, N., Lichtfouse, E., Eds.; Environmental Chemistry for a Sustainable World; Springer International Publishing: Cham, Switzerland, 2021; Volume 1, pp. 205-272. ISBN 9783030449247.

2. Mota, A.H.; Rijo, P.; Molpeceres, J.; Reis, C.P. Broad overview of engineering of functional nanosystems for skin delivery. Int. J. Pharm. 2017, 532, 710-728. [CrossRef]

3. Mota, A.H.; Sousa, A.; Figueira, M.; Amaral, M.; Sousa, B.; Rocha, J.; Fattal, E.; Almeida, A.J.; Reis, C.P. Natural-based consumer health nanoproducts: Medicines, cosmetics, and food supplements. In Handbook of Functionalized Nanomaterials for Industrial Applications; Hussain, C.M., Ed.; Micro and Nano Technologies; Elsevier: Amsterdam, The Netherlands, 2020; pp. 527-578, ISBN 9780128167885.

4. Mota, A.H.; Duarte, N.; Serra, A.T.; Ferreira, A.; Bronze, M.R.; Custódio, L.; Gaspar, M.M.; Simões, S.; Rijo, P.; Ascensão, L.; et al. Further Evidence of Possible Therapeutic Uses of Sambucus nigra L. Extracts by the Assessment of the In Vitro and In Vivo Anti-Inflammatory Properties of Its PLGA and PCL-Based Nanoformulations. Pharmaceutics 2020, 12, 1181. [CrossRef] [PubMed] 
5. Mota, A.H.; Andrade, J.M.; Rodrigues, M.J.; Custódio, L.; Bronze, M.R.; Duarte, N.; Baby, A.; Rocha, J.; Gaspar, M.M.; Simões, S.; et al. Synchronous insight of in vitro and in vivo biological activities of Sambucus nigra L. extracts for industrial uses. Ind. Crops Prod. 2020, 154, 1-11. [CrossRef]

6. Leverett, J.C.; Chandra, A.; Rana, J.; Fast, D.J.; Missler, S.R.; Flower, D.M. Extracts of durian fruit for use in skin care compositions. U.S. Patent Application No. 11/655,015, 24 May 2007.

7. Liotta, A.; Unnur, P.; Universio, P. Role of collagenases in tumor cell invasion. Cancer Metastasis Rev. 1982, 288, 277-288. [CrossRef]

8. Fisher, G.J.; Kang, S.; Varani, J.; Bata-Csorgo, Z.; Wan, Y.; Datta, S.; Voorhees, J.J. Mechanisms of photoaging and chronological skin aging. Arch. Dermatol. 2002, 138, 1462-1470. [CrossRef]

9. Ricciarelli, R.; Maroni, P.; Özer, N.; Zingg, J.M.; Azzi, A. Age-dependent increase of collagenase expression can be reduced by $\alpha$-tocopherol via protein kinase C inhibition. Free Radic. Biol. Med. 1999, 27, 729-737. [CrossRef]

10. Krutmann, J. Skin Aging. In Nutrition Health Skin; Springer: Berlin/Heidelberg, Germany, 2010; pp. 15-24. ISBN 9783642122637.

11. Oancea, A.M.; Onofrei, C.; Turturică, M.; Bahrim, G.; Râpeanu, G.; Stănciuc, N. The kinetics of thermal degradation of polyphenolic compounds from elderberry (Sambucus nigra L.) extract. Food Sci. Technol. Int. 2018, 24, 361-369. [CrossRef]

12. Carlsen, C.; Stapelfeldt, H. Light sensitivity of elderberry extract. Quantum yields for photodegradation in aqueous solution. Food Chem. 1997, 60, 383-387. [CrossRef]

13. Rijo, P.; Matias, D.; Fernandes, A.; Simões, M.; Nicolai, M.; Reis, C. Antimicrobial plant extracts encapsulated into polymeric beads for potential application on the skin. Polymers 2014, 6, 479-490. [CrossRef]

14. Sudhakar, C.K.; Upadhyay, N.; Jain, S.; Charyulu, R.N. Ethosomes as Non-invasive Loom for Transdermal Drug Delivery System. In Nanomedicine and Drug Delivery-Adavnces in Nanoscience and Nanotechnology; Sebastian, M., Ninan, N., Haghi, A.K., Eds.; CRC Press/Taylor \& Francis: Oakville, ON, Canada, 2012; Volume 1, pp. 1-16. ISBN 9781466560079.

15. Kaul, S.; Gulati, N.; Verma, D.; Mukherjee, S.; Nagaich, U. Role of Nanotechnology in Cosmeceuticals: A Review of Recent Advances. J. Pharm. 2018, 2018, 1-19. [CrossRef]

16. Lohani, A.; Verma, A.; Joshi, H.; Yadav, N.; Karki, N. Nanotechnology-Based Cosmeceuticals. ISRN Dermatol. 2014, 2014 , 1-14. [CrossRef]

17. A Guidebook to Particle Size Analysis; Horiba Scientific: Piscataway, NJ, USA, 2016; Available online: https:/ / docplayer.net/184775 98-A-guidebook-to-particle-size-analysis.html (accessed on 13 January 2017).

18. Cândido, T.M.; De Oliveira, C.A.; Ariede, M.B.; Velasco, M.V.R.; Rosado, C.; Baby, A.R. Safety and Antioxidant Efficacy Profiles of Rutin-Loaded Ethosomes for Topical Application. AAPS PharmSciTech 2018, 19, 1773-1780. [CrossRef]

19. Eaton, P.; Quaresma, P.; Soares, C.; Neves, C.; de Almeida, M.P.; Pereira, E.; West, P. A direct comparison of experimental methods to measure dimensions of synthetic nanoparticles. Ultramicroscopy 2017, 182, 179-190. [CrossRef] [PubMed]

20. Liu, Y.; Tan, J.; Thomas, A.; Ou-Yang, D.; Muzykantov, V.R. The shape of things to come: Importance of design in nanotechnology for drug delivery. Ther. Deliv. 2012, 3, 181-194. [CrossRef] [PubMed]

21. Scopel, M.; Mentz, L.A.; Henriques, A.T. Comparative analysis of sambucus nigra and sambucus australis flowers: Development and validation of an HPLC method for raw material quantification and preliminary stability study. Planta Medica 2010, 76, 1026-1031. [CrossRef] [PubMed]

22. Testoni, L.D.; De Souza, A.B.; De Krueger, C.M.A.; Quintão, N.L.M.; Couto, A.G.; Bresolin, T.M.B. Quantification of sambucus nigra (Adoxaceae) markers related to tincture stability. Nat. Prod. Commun. 2019, 14, 59-62. [CrossRef]

23. Oniszczuk, A.; Olech, M.; Oniszczuk, T.; Wojtunik-Kulesza, K.; Wójtowicz, A. Extraction methods, LC-ESI-MS/MS analysis of phenolic compounds and antiradical properties of functional food enriched with elderberry flowers or fruits. Arab. J. Chem. 2019, 12, 4719-4730. [CrossRef]

24. Barupal, A.K.; Gupta, V.; Ramteke, S. Preparation and Characterization of Ethosomes for Topical delivery of Aceclofenac. Indian J. Pharm. Sci. 2010, 72, 582-586.

25. Iizhar, S.A.; Syed, I.A.; Satar, R.; Ansari, S.A. In vitro assessment of pharmaceutical potential of ethosomes entrapped with terbinafine hydrochloride. J. Adv. Res. 2016, 7, 453-461. [CrossRef]

26. Dhiman, A.; Singh, D.; Fatima, K.; Zia, G. Development of Rutin Ethosomes for Enhanced Skin Permeation. Int. J. Tradit. Med. Appl. 2019, 1, 4-10. [CrossRef]

27. Jacob, M.; Agrawal, N.; Paul, D. Development, characterization \& in vitro skin permeation of rutin ethosomes as a novel vesicular carrier. Int. J. Biomed. Res. 2017, 8, 559-566.

28. Park, S.N.; Lee, H.J.; Gu, H.A. Enhanced skin delivery and characterization of rutin-loaded ethosomes. Korean J. Chem. Eng. 2014, 31, 485-489. [CrossRef]

29. Proksch, E. pH in nature, humans and skin. J. Dermatol. 2018, 45, 1044-1052. [CrossRef] [PubMed]

30. Chandra, A.; Aggarwal, G.; Manchanda, S.; Narula, A. Development of Topical Gel of Methotrexate Incorporated Ethosomes and Salicylic Acid for the Treatment of Psoriasis. Pharm. Nanotechnol. 2019, 7, 362-374. [CrossRef]

31. Marto, J.; Baltazar, D.; Duarte, A.; Fernandes, A.; Gouveia, L.; Militão, M.; Salgado, A.; Simões, S.; Oliveira, E.; Ribeiro, H.M. Topical gels of etofenamate: In vitro and in vivo evaluation. Pharm. Dev. Technol. 2015, 20, 710-715. [CrossRef] [PubMed]

32. Andleeb, M.; Shoaib Khan, H.M.; Daniyal, M. Development, Characterization and Stability Evaluation of Topical Gel Loaded with Ethosomes Containing Achillea millefolium L. Extract. Front. Pharmacol. 2021, 12, 1-11. [CrossRef] 
33. Pannu, A.; Goyal, R.K.; Ojha, S.; Nandave, M. Naringenin: A Promising Flavonoid for Herbal Treatment of Rheumatoid Arthritis and Associated Inflammatory Disorders. In Bioactive Food as Dietary Interventions for Arthritis and Related Inflammatory Diseases; Elsevier: Amsterdam, The Netherlands, 2019; pp. 343-354. ISBN 9780128138205.

34. Zofia, N.Ł.; Martyna, Z.D.; Aleksandra, Z.; Tomasz, B. Comparison of the Antiaging and Protective Properties of Plants from the Apiaceae Family. Oxid. Med. Cell. Longev. 2020, 2020. [CrossRef] [PubMed]

35. Karim, N.A. Ethosomal nanocarriers: The impact of constituents and formulation techniques on ethosomal properties, in vivo studies, and clinical trials. Int. J. Nanomed. 2016, 11, 2279-2304.

36. Van Hoogevest, P.; Wendel, A. Review Article The use of natural and synthetic phospholipids as pharmaceutical excipients A. Eur. J. Lipid Sci. Technol. 2014, 116, 1088-1107. [CrossRef]

37. Colombo, I.; Sangiovanni, E.; Maggio, R.; Mattozzi, C.; Zava, S.; Corbett, Y.; Fumagalli, M.; Carlino, C.; Corsetto, P.A.; Scaccabarozzi, D.; et al. HaCaT Cells as a Reliable In Vitro Differentiation Model to Dissect the Inflammatory/Repair Response of Human Keratinocytes. Mediat. Inflamm. 2017, 2017, 1-12. [CrossRef]

38. Marques, P.; Marto, J.; Gonçalves, L.M.; Pacheco, R.; Fitas, M.; Pinto, P.; Serralheiro, M.L.M.; Ribeiro, H. Cynara scolymus L.: A promising Mediterranean extract for topical anti-aging prevention. Ind. Crops Prod. 2017, 109, 699-706. [CrossRef]

39. Islam, M.T.; Ciotti, S.; Ackermann, C. Rheological Characterization of Topical Carbomer Gels Neutralized to Different pH. Pharm. Res. 2004, 21, 1192-1199. [CrossRef]

40. Feil, H.; Bae, Y.H.; Feijen, J.; Kim, S.W. Mutual influence of $\mathrm{pH}$ and temperature on the swelling of ionizable and thermosensitive hydrogels. Macromolecules 1992, 25, 5528-5530. [CrossRef]

41. Barry, B.W.; Meyer, M.C. The rheological properties of carbopol gels I. Continuous shear and creep properties of carbopol gels. Int. J. Pharm. 1979, 2, 1-25. [CrossRef]

42. Kunitz, M. Syneresis and swelling of gelatin. J. Gen. Physiol. 1928, 12, 289-312. [CrossRef]

43. Dave, V.; Bhardwaj, N.; Gupta, N.; Tak, K. Herbal ethosomal gel containing luliconazole for productive relevance in the field of biomedicine. 3 Biotech 2020, 10, 1-15. [CrossRef]

44. Jain, S.; Patel, N.; Madan, P.; Lin, S. Formulation and rheological evaluation of ethosome-loaded carbopol hydrogel for transdermal application. Drug Dev. Ind. Pharm. 2016, 42, 1315-1324. [CrossRef] [PubMed]

45. Walicka, A.; Falicki, J. Rheology of Drugs for Topical and Transdermal Delivery. Int. J. Appl. Mech. Eng. 2019, $24,179-198$. [CrossRef]

46. Ortan, A.; Parvu, C.D.; Ghica, M.V.; Popescu, L.M.; Ionita, L. Rheological study of a liposomal hydrogel based on carbopol. Rom. Biotechnol. Lett. 2011, 16, 47-54.

47. Pawar, J.; Narkhede, R.; Amin, P.; Tawde, V. Design and Evaluation of Topical Diclofenac Sodium Gel Using Hot Melt Extrusion Technology as a Continuous Manufacturing Process with Kolliphor ${ }^{\circledR}$ P407. AAPS PharmSciTech 2017, 18, 2303-2315. [CrossRef]

48. Bonacucina, G.; Cespi, M.; Misici-Falzi, M.; Palmieri, G.F. Rheological, adhesive and release characterisation of semisolid Carbopol/tetraglycol systems. Int. J. Pharm. 2006, 307, 129-140. [CrossRef]

49. Rijo, P.; Falé, P.L.; Serralheiro, M.L.; Simões, M.F.; Gomes, A.; Reis, C. Optimization of medicinal plant extraction methods and their encapsulation through extrusion technology. Meas. J. Int. Meas. Confed. 2014, 58, 249-255. [CrossRef]

50. Rouser, G.; Fleischer, S.; Yamamoto, A. Two dimensional thin layer chromatographic separation of polar lipids and determination of phospholipids by phosphorus analysis of spots. Lipids 1970, 5, 494-496. [CrossRef]

51. Gaspar, M.M.; Cruz, A.; Penha, A.F.; Reymão, J.; Sousa, A.C.; Eleutério, C.V.; Domingues, S.A.; Fraga, A.G.; Filho, A.L.; Cruz, M.E.M.; et al. Rifabutin encapsulated in liposomes exhibits increased therapeutic activity in a model of disseminated tuberculosis. Int. J. Antimicrob. Agents 2008, 31, 37-45. [CrossRef] [PubMed]

52. Silva, C.O.; Rijo, P.; Molpeceres, J.; Figueiredo, I.V.; Ascensão, L.; Fernandes, A.S.; Roberto, A.; Reis, C.P. Polymeric nanoparticles modified with fatty acids encapsulating betamethasone for anti-inflammatory treatment. Int. J. Pharm. 2015, 493, 271-284. [CrossRef] [PubMed]

53. Vijayalakshmi, S.; Karthika, T.N.; Mishra, A.K.; Chandra, T.S. Spectrofluorimetric method for the estimation of total lipids in Eremothecium ashbyii fungal filaments using Nile blue and avoiding interference of autofluorescent riboflavin. J. Microbiol. Methods 2003, 55, 99-103. [CrossRef]

54. Mota, A.H.; Direito, R.; Carrasco, M.P.; Rijo, P.; Ascensão, L.; Silveira Viana, A.; Rocha, J.; Eduardo-Figueira, M.; João Rodrigues, M.; Custódio, L.; et al. Combination of hyaluronic acid and PLGA particles as hybrid systems for viscosupplementation in osteoarthritis. Int. J. Pharm. 2019, 559, 13-22. [CrossRef] [PubMed]

55. Kumar, P.; Choonara, Y.E.; Pillay, V. In silico analytico-mathematical interpretation of biopolymeric assemblies: Quantification of energy surfaces and molecular attributes via atomistic simulations. Bioeng. Transl. Med. 2018, 3, 222-231. [CrossRef] [PubMed]

56. Santos-Rebelo, A.; Kumar, P.; Pillay, V.; Choonara, Y.E.; Eleutério, C.; Figueira, M.; Viana, A.S.; Ascensão, L.; Molpeceres, J.; Rijo, P.; et al. Development and mechanistic insight into the enhanced cytotoxic potential of parvifloron D albumin nanoparticles in EGFR-overexpressing pancreatic cancer cells. Cancers 2019, 11, 1733. [CrossRef]

57. Mota, A.H.; Andrade, J.M.; Ntungwe, E.N.; Pereira, P.; Cebola, M.J.; Bernardo-Gil, M.G.; Molpeceres, J.; Rijo, P.; Viana, A.S.; Ascensão, L.; et al. Green extraction of Sambucus nigra L. for potential application in skin nanocarriers. Green Mater. 2020, 8 , 181-193. [CrossRef] 
58. Jackson, J.K.; Zhao, J.; Wong, W.; Burt, H.M. The inhibition of collagenase induced degradation of collagen by the galloylcontaining polyphenols tannic acid, epigallocatechin gallate and epicatechin gallate. J. Mater. Sci. Mater. Med. 2010, 21, 1435-1443. [CrossRef] [PubMed]

59. Santos-Rebelo, A.; Garcia, C.; Eleutério, C.; Bastos, A.; Coelho, S.C.; Coelho, M.A.N.; Molpeceres, J.; Viana, A.S.; Ascensão, L.; Pinto, J.F.; et al. Development of parvifloron D-loaded smart nanoparticles to target pancreatic cancer. Pharmaceutics 2018, 10, 216. [CrossRef]

60. Delfim Fernando Gonçalves dos Santos Absorção percutânea-geles de carbopol contendo fentiazac, Faculdade de Farmacia do Porto. 1995. Available online: http:/ / hdl.handle.net/10216/10158 (accessed on 31 October 2019).

61. Reis, C.; Antunes, A.F.; Rijo, P.; Baptista, M.; Mota, J.P.; Monteiro Rodrigues, L. A novel topical association with zinc oxide, chamomile and aloe vera extracts-stability and safety studies. Biomed. Biopharm. Res. 2015, 12, 251-264. [CrossRef]

62. EMA/CPMC/ICH/2736/99 ICH Topic Q1A (R2). 2003. Available online: https://www.ema.europa.eu/en/documents/scientificguideline/ich-q-1-r2-stability-testing-new-drug-substances-products-step-5_en.pdf (accessed on 6 August 2020).

63. Braden, M. Tissue Conditioners: II. Rheologic Properties. J. Dent. Res. 1970, 49, 496-501. [CrossRef]

64. Reis, C.P.; Gomes, A.; Rijo, P.; Candeias, S.; Pinto, P. Evaluation of a New Topical Treatment for Acne with Azelaic Acid-Loaded Nanoparticles. Microsc. Microanal. 2013, 19, 1141-1150. [CrossRef] [PubMed]

65. Marzulli, F.N.; Maibach, H.I. Contact allergy: Predictive testing in man. Contact Dermatitis 1976, 2, 1-17. [CrossRef] [PubMed]

66. PhD Trials Patch Test study protocol n ${ }^{\circ}$ PT.02.01/ final03, RNEC $n^{\circ} 127504$. 